NBER WORKING PAPER SERIES

\title{
SEAM BIAS, MULTIPLE-STATE, MULTIPLE-SPELL DURATION MODELS AND THE EMPLOYMENT DYNAMICS OF DISADVANTAGED WOMEN
}

\author{
John C. Ham \\ Xianghong Li \\ Lara Shore-Sheppard \\ Working Paper 15151 \\ http://www.nber.org/papers/w15151
}

\author{
NATIONAL BUREAU OF ECONOMIC RESEARCH \\ 1050 Massachusetts Avenue \\ Cambridge, MA 02138 \\ July 2009
}

This paper was previously circulated under the title "Analyzing Movements over Time in Employment Status and Welfare Participation while Controlling for Seam Bias using the SIPP." This work is supported by the NSF. We are grateful for comments received at the IRP Summer Research Workshop "Current Research on the Low-Income Population," Madison, WI, June 19-22, 2006, as well as seminars at many universities and branches of the Federal Reserve Bank. We are particularly grateful to Geert Ridder, Melvin Stephens, Lowell Taylor and Tiemen Woutersen for suggestions that significantly improved the paper. Sandra Black, Mary Daly, Jose Lopez, Robert Moffitt, Bruce Meyer and Soohyung Lee also made very helpful remarks on an earlier draft. Eileen Kopchik provided, as usual, outstanding programming in deciphering the SIPP. Any opinions, findings and conclusions or recommendations in this material are those of the authors and do not necessarily reflect the views of the National Science Foundation. We are responsible for any errors. The views expressed herein are those of the author(s) and do not necessarily reflect the views of the National Bureau of Economic Research.

NBER working papers are circulated for discussion and comment purposes. They have not been peerreviewed or been subject to the review by the NBER Board of Directors that accompanies official NBER publications.

(C) 2009 by John C. Ham, Xianghong Li, and Lara Shore-Sheppard. All rights reserved. Short sections of text, not to exceed two paragraphs, may be quoted without explicit permission provided that full credit, including $(\mathrm{C}$ notice, is given to the source. 
Seam Bias, Multiple-State, Multiple-Spell Duration Models and the Employment Dynamics of Disadvantaged Women

John C. Ham, Xianghong Li, and Lara Shore-Sheppard

NBER Working Paper No. 15151

July 2009

JEL No. C41,C42,I38,J22

\begin{abstract}
Panel surveys generally suffer from "seam bias"--too few transitions observed within reference periods and too many reported between interviews. Seam bias is likely to affect duration models severely since both the start date and the end date of a spell may be misreported. In this paper we examine the employment dynamics of disadvantaged single mothers in the Survey of Income and Program Participation (SIPP) while correcting for seam bias in reported employment status. We develop parametric misreporting models for use in multi-state, multi-spell duration analysis; the models are identified if misreporting parameters are the same for fresh and left-censored spells of the same type. We extend these models to allow misreporting to depend on individual characteristics and for a certain fraction of the sample never to misreport. These extensions are informative about misreporting, but do not affect estimates of the hazard functions. We compare our results to two approaches used previously: i) using only data on the last month of reference periods and ii) adding a dummy variable for the last month of the reference periods. We find that there are important differences between our estimates and those obtained from ii), and very important differences between our estimates and those obtained from i). Finally, we also consider three alternative models of misreporting and are able to reject them based on aggregates of our micro data.
\end{abstract}

John C. Ham

University of Maryland

Department of Economics

3105 Tydings Hall

College Park, MD 20742

johnham@usc.edu

Xianghong Li

Department of Economics

Vari Hall 1068, 4700 Keele St

Toronto, ON, M3J 1P3, Canada

xli@econ.yorku.ca
Lara Shore-Sheppard

Department of Economics

Williams College

South Academic Building

24 Hopkins Hall Drive

Williamstown, MA 01267

and NBER

1shore@williams.edu 


\section{Introduction}

Panel surveys generally suffer from "seam bias." This refers to the fact that transitions or changes in status within reference periods are underreported while too many transitions or changes are reported as occurring between interviews. To the best of our knowledge, this effect was noted first by Czajka (1983) for benefit receipt in the U.S. Income Survey Development Program. Since then seam effects have been documented for various longitudinal surveys, e.g. the Current Population Survey, the Panel Study of Income Dynamics, the Canadian Survey of Labour and Income Dynamics, the European Community Household Panel Survey, the British Household Panel Survey, the Survey of Income and Program Participation (SIPP), and banking data. ${ }^{1}$ Lemaitre (1992) concludes that all current longitudinal surveys appear to be affected by seam problems, regardless of differences in the length of recall periods or other design features. Seam bias poses an important problem for the SIPP, which was intended to provide accurate reporting of labor force and program participation dynamics at the monthly level. The existence of seam bias plausibly would be most serious for estimating duration models, since it affects the timing of transitions. The Census Bureau, which collects the SIPP, has long recognized this problem and has attempted to reduce it in the SIPP, most recently by incorporating "dependent interviewing" procedures in the 2004 panel of the survey. Notwithstanding the adoption of such procedures, which explicitly link the wording of current interview questions to information provided in the preceding interview, seam bias continues to be a substantial problem in the SIPP (Moore 2008).

Pischke (1995) proposes a method for dealing with seam bias in the SIPP when using data on continuous variables such as income. Here we address the issues that occur with duration models when seam bias is present; the extension to other limited dependent variable models is straightforward. Specifically, we allow for seam bias when estimating monthly discrete time duration models to analyze the employment dynamics of single mothers with a high school education or less, a group that has been the focus of much recent policy. We estimate monthly transition rates into and out of employment for the period 1986-1995, prior to the replacement of Aid to Families with Dependent Children (AFDC) with Temporary Assistance to Needy Families (TANF). Transitions into and out of employment are of crucial importance to policymakers, as they determine unemployment rates, poverty rates and the overall well-being of low-income individuals. The SIPP is particularly well-suited to estimate such models because of its detailed monthly information on employment and program participation.

\footnotetext{
${ }^{1}$ See Moore (2008) for a summary of seam bias research. See Chakravarty and Sarkar (1999) for information about seam bias in banking data.
} 
With the exception of studies focusing on job training outcomes (see, for example, Ham and LaLonde (1996) and Eberwein, Ham and LaLonde (1997) who analyze employment dynamics using data from the National Supported Work and Job Training Partnership Act experiments, respectively) there have been relatively few studies of employment dynamics for less-educated women. (An exception is Aaronson and Pingle 2006, who study employment dynamics among single mothers in the 1990-2001 SIPP panels.) On the other hand, welfare dynamics for less-educated women have been examined in numerous studies, e.g. Blank and Ruggles (1996), Acs, Philips, and Nelson (2003) and Ribar (2005). Note that employment dynamics and welfare dynamics will differ, as single mothers can work and collect welfare simultaneously, and can certainly be out of employment and off welfare simultaneously. A clear understanding of employment dynamics is essential for policy; for example policy makers are likely to be very interested in the determinants of employment duration, since short employment spells prevent individuals from acquiring on-the-job human capital. Further, as we show below, our results have important implications for the debate over whether transitions into non-employment are pro-cyclical (Elsby, Michaels, and Solon 2009 and Shimer 2005a, 2005b).

Most of the welfare duration studies have estimated some form of discrete time hazard models using the SIPP or other panel surveys. ${ }^{2}$ Consequently, these studies have been forced to confront the seam bias problem. The approaches used in the literature to address this problem can be grouped into three types. One approach is to use the monthly data and to include a dummy variable for the last month of the reference period in addition to an indicator variable for each reference period (known as a "wave" in the SIPP). Blank and Ruggles (1996) use this approach in their study of entry into and exit from welfare and Food Stamps using the 1986 and 1987 SIPP panels. Fitzgerald (2004) uses a similar approach in his study of welfare exits using the 1986, 1988, 1990, and 1992 SIPP panels. A second approach involves collapsing the monthly data into data by wave and setting participation and employment indicator variables to be 1 if respondents were employed or on welfare in a sub-period of a wave. Acs, Philips, and Nelson (2003) use the 1990 and 1996 SIPP panels to focus on welfare entry, setting welfare participation to be 1 for a wave if participation was reported in at least two of the four months in a wave, and zero otherwise. Ribar (2005) uses the 1992 and 1993 panels of the SIPP to examine welfare entry and exit, setting participation equal to one for a wave if participation was reported for at least one month in the wave, and zero otherwise. This redefines the concept of participation and will result in the loss of short spells. To see this, note that an individual could have a two-month spell of nonparticipation in a reference period but this spell would not be counted in the analysis. This approach will be especially

\footnotetext{
2 For example Gittleman (2001) and Hofferth, Stanhope, and Harris (2002) use data from the Panel Study of Income Dynamics (PSID) to estimate dynamic models of welfare exit or entry.
} 
problematic if used in modeling employment dynamics, since employment spells are often quite short for the disadvantaged population.

Another very common solution to the seam bias problem in the SIPP data is to use only the last month observation from each wave, dropping the three other months. (For example, Grogger 2004, Ham and Shore-Sheppard 2005b, and Aaronson and Pingle 2006 use this approach.) Two reasons are given for using the last month data. First, most transitions take place between waves, i.e. in the last month. However, as we show in Section 3, this reason ignores the fact that one loses almost one half of fresh spells (i.e. those starting after the beginning of the sample) by using only the last month data. Further, we show below that information on the timing of transitions that occur in months other than the last month is lost, potentially introducing severe distortions to the true employment and welfare participation patterns. Second, it is argued that using only the last month is preferable because many of the transitions in months other than the last month are likely to be due to imputation. ${ }^{3}$ However, for the time period we consider (1986-1993 SIPP panels), we find that about $80 \%$ of the transitions in the imputed data are reported to have occurred in the last (seam) month, while $50 \%$ of the transitions in the non-imputed data are reported to have taken place in the last month.

We propose a parametric approach to correct for seam bias in a duration model setting and use maximum likelihood to estimate the model. Our approach is most similar in spirit to that used by Pischke (1995) for continuous variables. We first develop a monthly discrete time duration model with parameters representing the propensity to under-report transitions in each of the first three months of the reference period by allocating them to the last month of the previous wave. (This form of misreporting will occur if respondents simply replace their actual employment status in the first three months of a wave with their month 4 employment status.) This form of misreporting is consistent with the findings of previous researchers on seam bias, including Goudreau, Oberheu and Vaughan 1984, who link AFDC income reporting in the Income Survey Development Program data to administrative records. We show that this model is identified without restricting the form of the duration dependence for fresh spells, but that this is not true for left-censored spells (i.e. spells which are in progress at the start of the sample). Thus we assume that left-censored employment (nonemployment) spells and fresh employment (non-employment) spells share the same misreporting parameters when we estimate a multiple-state, multiple-spell model of employment dynamics. Our

\footnotetext{
${ }^{3}$ For example, Grogger (2004, p.674) states “... some of the within-wave transitions that exist are due to the SIPP imputation procedures rather than changes in behavior (Westat 2001). Since most transitions are reported to occur between waves, I only make use of data from month 4 of each wave."
} 
models explicitly allow for the fact that if seam bias causes the end month of a spell to be mismeasured, it also causes the start month of the next spell to be mismeasured.

Next we consider three richer misreporting models to shed light on the underlying causes of seam effects. First, we consider the case where the misreporting probability varies with demographic characteristics. Second, we allow for the possibility that a fraction of people never misreport, and finally, we also let this fraction depend on demographics. The first richer model indicates Whites have a significantly lower probability of misreporting. This is consistent with the pattern found by Kalton and Miller (1991) for misreporting of a known Social Security payment increase in the SIPP 1984 panel and with the findings of Black, Sanders, and Taylor (2003) on education misreporting in the Census.

For comparison we also carry out the estimation of the duration models using two of the alternative models discussed previously: i) using only the last month data and ii) putting a dummy for the last month observations in the hazard and then adjusting the constant using the coefficient of this dummy variable. ${ }^{4}$ We find that there are important differences between our seam bias estimates and those obtained with a last month dummy, and very important differences between our seam bias estimates and those obtained using the last month data. We find a number of interesting empirical results concerning the employment dynamics of disadvantaged women. For example, we estimate the effect of changes in several policy and macro variables on the short term, intermediate term and long term fraction of time during which a woman is employed. These changes include states implementing positive incentives to leave welfare ("carrots"), changes in the overall unemployment rate or welfare benefits in states, states introducing punitive incentives to leave welfare ("sticks"), and changes in the minimum wage. Intriguingly, the first three changes have statistically significant effects in the expected direction while the last two changes do not. A small number of empirical studies (for example, Ashenfelter and Card 1981, Currie and Fallick 1996 and Campolieti, Fang and Gunderson 2005) have used individual panel data sets to estimate minimum wage effects on employment transition probabilities, and they mainly focus on the minimum wage effects on transitions out of employment. Our findings regarding the minimum wage are particularly notable because our models have taken into consideration the minimum wage effects on transitions out of and into employment simultaneously.

We find that when the overall unemployment rate increases: i) the hazard function for leaving left-censored and fresh non-employment spells falls; ii) the hazard function for leaving fresh employment spells increases; but iii) the hazard function for leaving a left-censored employment spell

\footnotetext{
${ }^{4}$ Previous researchers who used the month 4 dummy variable method did not adjust the constant. Not making this adjustment will lead to an underestimate of the hazard function at each duration.
} 
is unaffected. Elsby, Michaels, and Solon (2009) argue that that the higher unemployment rate during a recession is due to both longer unemployment spells (i.e. the non-employment hazards fall) and more unemployment spells (i.e. the employment hazards rise); Shimer (2005a, 2005b) argues that only the first effect occurs. None of these studies control for individual heterogeneity; when we do so and thus take into account changes in the composition of those in employment and nonemployment over the business cycle, we find both of these positions continue to have merit.

Of course, as with any study using a parametric model, there is the issue of whether we have the right model of misreporting behavior. To address this concern, we estimate several variants of our base model. In addition, there are several pieces of indirect evidence supporting our model. First, the telescoping behavior underlying all of our misreporting models is exactly the type of behavior that the 2004 revision of the SIPP aimed to minimize. Second, the findings of several previous studies support our model of misreporting behavior and our finding of a higher misreporting probability for minorities. Finally, we consider three alternative models of misreporting, but reject them on the basis of aggregate data from the SIPP. Thus we consider a wide range of possible behavior and find substantial support for our modeling strategy.

The paper proceeds as follows: In Section 2 we discuss the SIPP data and the extent of the seam bias problem. In Section 3 we discuss the problems that occur when one uses only the last month observations. In Section 4 we present our seam bias correction approach. We first outline the assumptions underlying our parametric approach, which we believe to be reasonable. We then outline our approach for estimating parametric single spell duration models in the presence of seam bias and discuss identification of these models. Finally, we consider the estimation of multi-spell, multi-state duration models with seam bias correction. We present our empirical results in Section 5 and conclude the paper in Section 6.

\section{Seam Bias and the SIPP Data}

Our primary data consist of the 1986-1993 panels of the SIPP. The SIPP was designed to provide detailed information on incomes and income sources, as well as on labor force and program participation, of U.S. individuals and households. Our sample is restricted to single mothers who have at most twelve years of schooling. Since we investigate employment status, we only consider women between the ages of 16 and 55.5 Although researchers investigating welfare durations often smooth out one-month spells, we use the original data with all one-month spells intact because employment status is often very unstable among low-educated women and it is common for them to

\footnotetext{
${ }^{5}$ Respondents are chosen based on their education and age at the beginning of the panel. If a single mother marries in the middle of the survey, we keep the observations before the marriage and treat the spell in progress at the time of marriage as right-censored.
} 
have very short employment and non-employment spells. ${ }^{6}$ Since we use state level variables such as maximum welfare benefits, minimum wage rates, unemployment rates, and whether the state obtained a welfare waiver and introduced positive incentives to leave welfare (carrots) or negative incentives to leave (sticks), we exclude women from the smaller states which are not separately identified in the SIPP.

The SIPP uses a rotation group design, with each rotation group consisting of about a quarter of the entire panel, randomly selected. For each calendar month, members of one rotation group are interviewed about the previous four months (the reference period or wave), and all rotation groups are interviewed over the course of any four month period. Calendar months are thus equally distributed among the months of the reference period. We call the four months within each reference period month 1, month 2, month 3 and month 4 . We will also refer to month 4 as the last month. The rotation design guarantees that approximately $25 \%$ of transitions should occur in months 1, 2, 3 and 4 respectively. Summary statistics show that for our sample more than $45.86 \%$ of job transitions (from non-employment to employment and vice-versa) are reported to occur in month 4 , the last month. This number is far greater than the $25 \%$ one would expect. This seam effect, which researchers have attributed to both too much change across waves and too little change within waves, is observed for most variables in the SIPP (see, e.g. Young 1989, Marquis and Moore 1990, Ryscavage 1988 and Moore 2008).7

As noted earlier, some, e.g. Grogger, have expressed concern that many of the off-seam transitions are simply the result of an imputation procedure by the Census Bureau, making their use suspect. In the SIPP, monthly data are imputed when a sample member either refuses to be interviewed or is unavailable for that interview (and a proxy interview cannot be obtained), or when someone who enters a sample household after the start of the panel leaves the household during the reference period. ${ }^{8}$ The Census Bureau indicates whether a monthly observation is imputed using a

\footnotetext{
${ }^{6}$ Hamersma (2006) investigates a unique Wisconsin administrative data set containing information from all Work Opportunity Tax Credit (WOTC) and Welfare-to-Work (WtW) Tax Credit applications. The majority of WOTC-certified workers in Wisconsin are either welfare recipients or food stamp recipients. She finds that over one-third of certified workers have fewer than 120 annual hours of employment (job duration), while another 29 percent of workers have fewer than 400 annual hours. Only a little over one-third of workers have annual employment of more than 400 hours. These administrative data show that a significant share of employment spells are less than one month among disadvantaged individuals. In our data it makes surprisingly little difference whether or not we smooth out the one-month spells.

${ }^{7}$ An experimental study of seam effects (Rips, Conrad, and Fricker 2003) suggests that seam effects may arise from respondents forgetting the timing of events together with "constant wave responding" in which respondents simply give the same answer for all four months of a wave.

${ }^{8}$ All adults in sampled households at the start of the panel are considered original sample members and are followed to any new address. Someone entering a sample household after the start of the panel is interviewed as a member of the household, but not followed if he or she leaves. In that case, the remaining months of a reference period after the departure will be imputed.
} 
variable INTVW, which equals 1 or 2 if a self or proxy interview is obtained (and hence the data are not imputed) and 3 or 4 if the respondent refuses to be interviewed or left, respectively (and hence the data are imputed). Using this variable, we compare the frequency of transitions at the seam in the imputed and non-imputed data (see Appendix Table A1). We find that approximately $50 \%$ of the transitions take place in month 4 in the non-imputed data, but about $81 \%$ take place in month 4 in the imputed data. That is, imputation accentuates seam bias rather than ameliorates it, negating part of the argument for omitting data on the first three months of a wave.

In our examination of employment dynamics using the SIPP, we follow Heckman and Singer (1984a) and the standard duration literature and distinguish between left-censored spells, which are in progress at the start of the sample, and fresh spells which begin after the start of the sample, for time spent both in and out of employment. ${ }^{9}$ The left-censored spells constitute the great majority of all spells in our data. For example, even in month 30 of the various SIPP samples, i.e. two and half years after the samples began, left-censored spells still constitute over sixty percent of both employment and non-employment spells. This raises two issues. First, using only fresh spells will not give an accurate picture of the employment dynamics of a typical woman in our sample, who is in a left-censored spell. Second, there is likely to be an important issue of selection in which women are observed in a fresh spell. Thus we analyze left-censored and fresh spells jointly to correct for this selection. ${ }^{10}$

Table 1 provides summary statistics (for the first month of each spell) for our sample of employment and non-employment spells. Panel A shows that single mothers in left-censored nonemployment spells are usually more disadvantaged than those in fresh non-employment spells. Specifically, those in left-censored non-employment spells are more likely to be minorities, less likely to have a full twelve years of schooling, less likely to have had a previous marriage, and are more likely to be disabled or have missing disability information than those in fresh non-employment spells. Also, the single mothers in left-censored non-employment spells tend to have more children, and their youngest children tend to be younger, compared to those in fresh non-employment spells. The two groups are similar in terms of age.

Panel B shows that those in left-censored employment spells tend to be less disadvantaged than those in fresh employment spells. Specifically, they are older, less likely to be minority group members, more likely to have twelve years of schooling, more likely to have had a previous marriage,

\footnotetext{
${ }^{9}$ Left-censored spells are sometimes called interrupted spells.

${ }^{10}$ While this selection bias may be important in principle, in practice Eberwein, Ham and LaLonde (1997) found it was not important in analyzing employment dynamics for similar women using data from the National Job Training Partnership Act Study.
} 
less likely to be disabled or have missing disability information, and tend to have both fewer children and older children than those in fresh employment spells.

\section{Problems in Measuring Spells Using Only the Last Month Observations}

As noted above, a common approach to the problem of seam bias is to use only the observations from the last month of the reference periods. Under this approach spells are constructed by acting as if we observe only the last month data for each wave. When there is a status change from the previous month 4 to the current month 4 , month 4 of the current wave is coded as the end of a spell. Here we construct three examples representative of our data to illustrate the problems that may arise when adopting this approach. In these examples, which are shown in Figures 1.1 - 1.3, we let $U, U^{\prime}, E$ and $E^{\prime}$ denote a fresh non-employment spell, a left-censored nonemployment spell, a fresh employment spell and a left-censored employment spell, respectively. In each figure, the numbers above the line indicate the survey months and the numbers below the line represent the reference period months. The first example illustrated in Figure 1.1 assumes that a respondent has four spells. The first spell is a left-censored non-employment spell ending in a month 1 , the second is a fresh employment spell ending in a month 3, the third is a fresh non-employment spell ending in another month 3, and the last spell is a right-censored fresh employment spell. Using only the last month data, we would treat this respondent's work history as consisting of a leftcensored non-employment spell lasting 32 months and a right-censored employment spell lasting four months. We would lose both a two-month fresh employment spell and a 24-month fresh nonemployment spell. In addition, we would miscalculate the spell length of both the left-censored and right-censored spells.

The next example, illustrated in Figure 1.2, shows that using only the last month data may lead to spell lengths being miscalculated, but does not necessarily lead to omission of spells. In Figure 1.2 we keep everything else the same as in Figure 1.1 and only shift the ending point of the second spell, which is also the starting point of the third spell. Now the second fresh employment spell lasts for five months with a month 4 in the middle of the spell. For such a case, using only last month data would not lead to the omission of the second and third spells, but only to the miscalculation of the length of all four spells.

Finally, we construct our last example to show how we can actually misclassify the type of a spell using only the last month data. Assume that a respondent has three spells as in Figure 1.3. The first spell is a left-censored non-employment spell ending in month 3 of the first reference period; the second is a completed fresh employment spell; and the third is a fresh non-employment spell censored at the end of the sample. Using only last month data we would record her work history as a 
left-censored employment spell and a fresh non-employment spell. From this example it is clear that we will lose all left-censored spells less than or equal to three months in length by switching to the last month data. In addition, using the last month data may lead to both miscalculating spell length and even misclassifying spell type for left-censored spells.

To recap, the above three examples show that by using only the last month data, we could lose some spells, miscalculate the length of spells, and misclassify the spell type. Further, the problem is more severe with short spells that are less than four months duration and that do not cover a month 4. From these examples it appears to be ambiguous whether using only the last month data will overestimate or underestimate the average duration. It is clear that in general using only the last month observations will lead to an overestimate of the length of left-censored spells. However, for fresh spells, using only the last month data may underestimate or overestimate the length of an observed fresh spell, since both the start and finish of a fresh spell could be mismeasured due to seam bias.

Of course, the above three examples compare the last month data to the true duration data, while in practice we do not know the true duration of spells. Thus the relevant comparison is the last month data versus the monthly data contaminated by seam bias, as some researchers only use the last month because of the seam bias. Here we would make two points. First, even in the presence of seam bias we still observe many short spells in our data, including spells falling between two interviews as in Figure 1.1.11 If some short spells are omitted due to seam bias, switching to using only the last month data certainly will not help us capture those omitted short spells. Second, the implications of Figures 1.1 to 1.3 also hold for comparisons of estimates based on the monthly data contaminated by seam bias (the SIPP data) and estimates based on only the last month observations from the contaminated data.

To shed more light on the comparison between the contaminated monthly data and the last month only data, we examine the number of completed spells and the empirical survivor functions for each data type. First, comparing the number of completed spells (which provide the empirical identification for the parameters of the hazard functions), we find that shift from using monthly data to the last month data results in the loss of about $47 \%$ of fresh employment spells, $48 \%$ of fresh non-employment spells, $20 \%$ of left-censored employment spells, and $18 \%$ of left-censored nonemployment spells. Second, when considering all spells (completed spells and right-censored spells), shifting from monthly data to the last month data still results in the loss of 34 to 35 percent of fresh spells. (See online Appendix Table A2, which presents distributions of spell length and total number

\footnotetext{
${ }^{11}$ An accurate measure of the frequency with which individuals fail to report short spells can only be obtained from matched administrative-survey data, which we do not have for this sample.
} 
of spells of monthly data versus last month data for all spells. ${ }^{12}$ ) However, it is difficult to ascertain the effect of using the last month data on spell lengths from Table A2 because of the right censored spells. Instead, we investigate the empirical survivor functions. Online Appendix Figures A.1 and A.2 show that using only the last month data will increase the estimated survivor function for leftcensored employment and non-employment spells by a considerable amount. Online Appendix Figures A.3 and A.4 show that this phenomenon is even more pronounced for fresh employment and non-employment spells.

These calculations indicate that shifting from the contaminated (by seam bias) data to only the last month data leads to omitting spells and overestimating the spell length. Moreover, using only the last month data will lead to a loss of efficiency since data from three-fourths of the months are being discarded, and nearly 55 percent of transitions occur in these months.

\section{Correcting for Seam Bias: A Parametric Approach}

We consider a model of misreporting behavior that allows us to save the valuable information contained in the monthly SIPP data and to address the seam bias problem. Specifically, we first develop a monthly single state discrete time duration model with three extra parameters that capture the misreporting of transitions. ${ }^{13}$ Under reasonable assumptions, we show that we can identify these parameters in our model. We then consider the extension to multi-state multi-spell duration model. Since the model is significantly over identified, we are able to use this to consider several extensions of the model.

\subsection{Notation}

We first set up our notation before discussing our assumptions. Let $M^{\text {obs }}=(m, l)$ represent a spell reported to end in month $m$ of reference period (wave) $l .{ }^{14}$ Note that $M^{\text {obs }}=(m, l)$ could be misreported because of seam bias. Further, let $M^{\text {true }}=(m, l)$ represent the fact that a spell truly ended in month $m$ of reference period $l$. The variable $m$ in $M^{\text {obs }}$ and $M^{\text {true }}$ assumes five possible values: $1,2,3,4$, or 0 , where $m=1,2,3$ or 4 indicates a transition in months $1,2,3$ or 4 , respectively, and $m=0$ indicates a right-censored spell ending with the survey. For our sample $l$ takes on the values from 1 to $L$, where $L$ is the number of waves, which depends on the specific SIPP panel

\footnotetext{
${ }^{12}$ The numbers of spells in the table are larger than those in Table 1 because here we have not imposed the selection criteria discussed in Section 2. The online Appendix is available at http://dept.econ.yorku.ca/ xli.

${ }^{13}$ See Romeo (2001) for a very different approach to dealing with seam bias in a duration model.

${ }^{14}$ The end of a spell can occur either because a transition took place or because the individual reached the end of the sample period.
} 
being used. ${ }^{15}$ For example, $M^{\text {obs }}=(4,4)$ indicates that a transition was reported to have occurred in month 4 of reference period 4 , while $M^{\text {true }}=(3,5)$ denotes that the transition actually occurred in month 3 of reference period 5 .

\subsection{Behavioral Assumptions}

As discussed in the introduction, seam bias is observed for many variables in the SIPP. The employment status variable we use to construct our measure of transitions is no exception. This constancy within waves of employment status in the SIPP is plausibly a feature of the interview structure. The respondent is first asked whether she had a job or business at any time during the previous four-month period; if the answer is yes, the respondent is then asked whether she had a job or business during all weeks of the period. Further questions are asked of individuals who report some time employed and some time not employed. This serves to determine the timing of their periods of employment and non-employment. For example, suppose an individual continues a spell of non-employment into a given wave and does not have a job for months 1 and 2 of the new wave, but she gets a job in month 3 that continues into month 4 of the wave. Given the interview structure, this individual may report that she has a job for the whole wave based on the fact she has a job in month 4, which is the month closest to (right before) the interview month. For this particular example, a non-employment spell ending in month 2 of the current reference period will be reported to end in month 4 of the previous reference period. Goudreau, Oberheu and Vaughan (1984) document this as the most common type of misreporting behavior for AFDC benefits in the Income Survey Development Program. ${ }^{16}$

Based on the interview structure, documented empirical evidence of seam bias in SIPP variables, and previous research based on survey and administrative data, we make the following main assumption: respondents sometimes move a transition in months 1, 2 or 3 of a given reference period to month 4 of the previous reference period. This shifting of transitions will occur if respondents sometimes report the employment status of month 4 for all months in the reference period. In terms of labor market state, this reflects the well-known phenomenon of telescoping (respondents recall that previous states are the same as the state in the current period, Sudman and Bradburn 1974, p.69), while in terms of transitions, it reflects the well-known phenomenon of "reverse telescoping" of transitions (respondents recall transitions as having occurred more distantly than in fact was the case, Lemaitre 1992). This is also similar to the third type of household behavior

15 There are seven waves in the 1986 and 1987 panels, six in the 1988 panel, eight in the 1990 and 1991 panels, ten in the 1992 panel, and nine in the 1993 panel.

${ }^{16}$ Their study is conducted by comparing respondents' reports obtained from interviews with administrative record information. 
considered by Pischke (1995, p.824), where he assumes that respondents report their permanent income (but not transitory income) in month 4 as applying to all months in the wave. We make the following five assumptions for each interview:

A1) the respondents report all transitions that occurred during reference period $l$ as occurring either in the true month or month 4 of reference period $l-1$;

A2) if a respondent reports that a transition happened in months 1,2 or 3 of a reference period, it is a truthful report;

A3) a respondent reports a transition that actually occurred in months 1, 2 or 3 of reference period $l$ as taking place in month 4 of reference period $l-1$ with some pre-specified (but unknown) probabilities $\gamma_{1}, \gamma_{2}$ and $\gamma_{3}$;

A4) if a transition truly happened in month 4 of a reference period, the respondent reports it as occurring in that month; and

A5) the true transition rate for a given duration does not depend on the reference period month, $m \cdot .^{17}$

Given these behavioral assumptions, ${ }^{18}$ we have the following conditional probabilities:

$$
\begin{aligned}
& P\left(M^{\text {obs }}=(m, l) \mid M^{\text {true }} \neq(m, l)\right)=0 \quad m=1,2,3 ; \\
& P\left(M^{o b s}=(4, l-1) \mid M^{\text {true }}=(m, l)\right)=\gamma_{m} \quad m=1,2,3 ; \\
& P\left(M^{\text {obs }}=(4, l) \mid M^{\text {true }}=(4, l)\right)=1 ; \\
& P\left(M^{\text {obs }}=(0, l) \mid M^{\text {true }}=(0, l)\right)=1 .
\end{aligned}
$$

\subsection{Correcting for Seam Bias in a Single Spell Model}

To illustrate the method in the simplest way, we first explore the problem involving a single spell of employment. We define the hazard function for individual $i$ as

$$
\lambda_{i}(t \mid \theta)=\frac{1}{1+\exp \left\{-h(t)-X_{i}(\tau+t) \beta-\theta_{i}\right\}}
$$

\footnotetext{
${ }^{17}$ This assumption is the consequence of the survey design. For ease of interviewing, the entire sample is randomly split into four rotation groups, and one rotation group (1/4 of the sample) is interviewed each calendar month. Each rotation group in a SIPP panel is interviewed once every four months about employment and program participation during the previous four months.

${ }^{18}$ Our assumptions rule out the possibility that individuals forget about very short spells that fall between two interviews. As discussed before, without administrative data linked to the SIPP data we have no way of verifying the truth of this assumption.
} 
where $t$ denotes current duration, $h(t)$ denotes duration dependence, $\tau$ denotes the calendar time of the start of the spell ( $\tau$ is suppressed in the following expressions), and $X_{i}(\tau+t)$ denotes a (possibly) time changing explanatory variable. Further, $\theta_{i}$ denotes unobserved heterogeneity, and following Heckman and Singer (1984b), we assume that it is i.i.d. across $i$ and is drawn from a discrete distribution function with points of support $\theta_{1}, \ldots, \theta_{J-1}, \theta_{J}$ and associated probabilities $p_{1}, \ldots, p_{J-1}$ and $p_{J}=1-\sum_{k=1}^{J-1} p_{k} \cdot{ }^{19}$ For example, if a spell lasts $K$ months, the contribution to the likelihood function for individual $i$ is

$$
L_{i}(K)=\sum_{j=1}^{J} p_{j} \lambda_{i}\left(K \mid \theta_{j}\right) \prod_{t=1}^{K-1}\left(1-\lambda_{i}\left(t \mid \theta_{j}\right)\right) .
$$

For notational simplicity, we drop the individual subscript $i$ in what follows.

Based on our behavioral assumptions, it is straightforward to derive the likelihood function given that we observe $M^{o b s}=(m, l)$, and the reported length of the spell, dur ${ }^{o b s}$, both of which potentially have been contaminated by seam bias. ${ }^{20}$ The contribution to the likelihood function for a completed spell of observed length $K$ that ends in month 1 of reference period $l$ is given by:

$$
\begin{aligned}
& P\left(M^{\text {obs }}=(1, l), \text { dur }^{\text {obs }}=K\right) \\
& =P\left(M^{\text {obs }}=(1, l), M^{\text {true }}=(1, l), d u r^{\text {true }}=K\right)+P\left(M^{\text {obs }}=(1, l), M^{\text {true }} \neq(1, l), d u r^{\text {true }} \neq K\right) .
\end{aligned}
$$

Since the second term is zero by assumption A2, we have

$$
\begin{aligned}
& P\left(M^{\text {obs }}=(1, l), \text { dur }^{\text {obs }}=K\right)=P\left(M^{\text {obs }}=(1, l), M^{\text {true }}=(1, l),\right. \text { dur } \\
& =P\left(M^{\text {true }}=K\right) \\
& =\left(1-\gamma_{1}\right) L(K),
\end{aligned}
$$

In (4.7) we have used the implication of assumption A3 that

$$
P\left(M^{\text {obs }}=(1, l) \mid M^{\text {true }}=(1, l), \text { dur } r^{\text {true }}=K\right)=\left(1-\gamma_{1}\right) \text {. }
$$

Moreover,

$$
P\left(M^{\text {true }}=(1, l) \mid d u r^{\text {true }}=K\right)=1 \text { and } P\left(d u r^{\text {true }}=K\right)=L(K) .
$$

Similarly, if a transition is reported to end in month 2 or month 3 of reference period $l$, and to have lasted for $K$ months, we have

${ }^{19}$ Our analysis is equally applicable to any other choice for the discrete time hazard function.

${ }^{20}$ Here we assume that seam bias affects only the end date, and not the start date, of a spell. We relax this assumption when we consider multiple spell data. 


$$
\begin{aligned}
& P\left(M^{o b s}=(2, l), d u r^{o b s}=K\right)=\left(1-\gamma_{2}\right) \cdot L(K) \text { and } \\
& P\left(M^{o b s}=(3, l), d u r^{o b s}=K\right)=\left(1-\gamma_{3}\right) \cdot L(K) .
\end{aligned}
$$

Finally, the contribution to the likelihood function of a completed spell of observed length $K$ that is observed to end in month 4 of reference period $l$ is given by

$$
\begin{aligned}
& P\left(M^{\text {obs }}=(4, l), d u r^{\text {obs }}=K\right) \\
& =P\left(M^{\text {obs }}=(4, l), M^{\text {true }}=(1, l+1), d u r^{\text {true }}=K+1\right)+P\left(M^{\text {obs }}=(4, l), M^{\text {true }}=(2, l+1), d u r^{\text {true }}=K+2\right)+ \\
& P\left(M^{\text {obs }}=(4, l), M^{\text {true }}=(3, l+1), d u r^{\text {true }}=K+3\right)+P\left(M^{\text {obs }}=(4, l), M^{\text {true }}=(4, l), d u r^{\text {true }}=K\right) \\
& =P\left(M^{\text {obs }}=(4, l) \mid M^{\text {true }}=(1, l+1), d u r^{\text {true }}=K+1\right) \cdot P\left(M^{\text {true }}=(1, l+1) \mid d u r^{\text {true }}=K+1\right) \cdot P\left(d u r^{\text {true }}=K+1\right) \\
& +\left(M^{\text {obs }}=(4, l) \mid M^{\text {true }}=(2, l+1), d u r^{\text {true }}=K+2\right) \cdot P\left(M^{\text {true }}=(2, l+1) \mid d u r^{\text {true }}=K+2\right) \cdot P\left(d u r^{\text {true }}=K+2\right) \\
& +\left(M^{\text {obs }}=(4, l) \mid M^{\text {true }}=(3, l+1), d u r^{\text {true }}=K+3\right) \cdot P\left(M^{\text {true }}=(3, l+1) \mid d u r^{\text {true }}=K+3\right) \cdot P\left(d u r^{\text {true }}=K+3\right) \\
& +\left(M^{\text {obs }}=(4, l) \mid M^{\text {true }}=(4, l), d u r^{\text {true }}=K\right) \cdot P\left(M^{\text {true }}=(4, l) \mid d u r^{\text {true }}=K\right) \cdot P\left(d u r^{\text {true }}=K\right) .
\end{aligned}
$$

Note that $P\left(M^{\text {obs }}=(4, l) \mid M^{\text {true }}=(4, l)\right.$, dur $\left.r^{\text {true }}=K\right)=1$ by assumption A4, and $P\left(M^{o b s}=(4, l) \mid M^{\text {true }}=(j, l+1), d u r^{\text {true }}=K+j\right)=\gamma_{j}, j=1,2,3$, by assumption A3. Thus the

contribution of a spell that ends in month 4 of wave $l$ is

$$
P\left(M^{o b s}=(4, l), d u r^{o b s}=K\right)=\gamma_{1} L(K+1)+\gamma_{2} L(K+2)+\gamma_{3} L(K+3)+L(K) .
$$

A natural question to ask is whether the model is identified without restricting the form of the duration dependence. In Appendix 1 we show that a model with only duration dependence and misreporting parameters is (over) identified for fresh employment and non-employment spells, but is not identified for left-censored employment and non-employment spells, assuming that each type of spell has entirely different misreporting and duration dependence parameters. However, we also show that all parameters are identified if we assume that left-censored employment (nonemployment) spells and fresh employment (non-employment) spells share the same misreporting parameters, and thus we make this assumption below.

We also consider models where the misreporting probabilities depend on individual characteristics. For example, suppose the probabilities differ among Whites and non-Whites (African Americans and Hispanics). We now assume that the misreporting probability in reference period month $j$ for employment spells is given by

$$
\gamma_{j}^{E}=\frac{1}{1+\exp \left(-\alpha_{0 j}^{E}-\alpha_{1 j}^{E} N W\right)} \quad j=1,2,3,
$$


where $N W$ a dummy variable is equal to 1 if an individual is non-White and zero otherwise. We use an analogous specification for non-employment spells. Since one could estimate this model by simply estimating the base model separately for Whites and non-Whites with constant misreporting probabilities, and then use a minimum distance procedure to estimate the parameters in (4.11), this extended model is also identified. Below we find that the misreporting probabilities indeed vary significantly by race. Interestingly, the misreporting probabilities do not vary by level of education, independent of whether we let the misreporting probabilities depend on race.

\subsection{Correcting for Seam Bias in a Multiple Spell Model}

In a multiple spell discrete time duration model, correcting for seam bias complicates the likelihood function dramatically since adjusting a response error in one spell involves shifting not only the end of the current spell but also the start of the subsequent spell. This is a serious problem as respondents in our sample have up to seven spells and a respondent can have several spells ending in month 4 in her history.

We estimate a discrete time duration model with multiple spells, duration dependence and unobserved heterogeneity. Due to the presence of unobserved heterogeneity and the lack of information on the start date, it is extremely complicated to derive the density function for time remaining in a left-censored spell using the same parameters as for fresh spells. Thus we continue to use separate hazard functions for the left-censored spells (Heckman and Singer 1984a). We allow the unobserved heterogeneity terms to be correlated across different types of spells.

As noted above, for identification we let the employment spells, both left-censored and fresh, share one set of seam bias parameters, $\gamma_{1}^{E}, \gamma_{2}^{E}$, and $\gamma_{3}^{E}$ as defined in equation (4.2), while we specify another set of parameters, $\gamma_{1}^{U}, \gamma_{2}^{U}$ and $\gamma_{3}^{U}$, which represent the seam bias associated with nonemployment spells. As defined in Section 3, we let $U^{\prime}$ and $U$ represent left-censored and fresh non-employment spells respectively, and let $E^{\prime}$ and $E$ represent left-censored and fresh employment spells respectively. ${ }^{21}$ We follow standard practice and specify the unobserved heterogeneity corresponding to these four types of spells through a vector $\theta=\left(\theta_{U}, \theta_{U^{\prime}}, \theta_{E}, \theta_{E^{\prime}}\right)$, and assume that $\theta$ is distributed independently across individuals and is fixed across spells for a given individual. Following McCall (1996) we let $\theta$ follow a discrete distribution with points of support $\theta_{1}, \theta_{2}, \ldots, \theta_{J}$,

\footnotetext{
${ }^{21}$ As we show in the previous section, we cannot let the seam bias parameters differ between left-censored and fresh spells of the same type.
} 
(where, e.g., $\theta_{1}=\left(\theta_{U 1}, \theta_{U^{\prime} 1}, \theta_{E 1}, \theta_{E^{\prime} 1}\right)$ ) and associated probabilities $p_{1}, p_{2}, \ldots, p_{J}$ respectively, where $p_{J}=1-\sum_{k=1}^{J-1} p_{k}$.

The following discussion is based on the relatively simple example in Figure 2, which covers all essential problems for multiple spells with seam bias. To distinguish among the four types of spells, we add a subscript to the transition indicators defined in Section 4.1 and duration indicators defined in Section 4.3. In Figure 2, the respondent reports three spells with a reporting history given by $\left\{M_{U^{\prime}}^{o b s}=(1,2), d u r_{U^{\prime}}^{o b s}=5, M_{E}^{o b s}=(4,3), d u r_{E}^{o b s}=7, M_{U}^{o b s}=(0,9), d u r_{U}^{o b s}=24\right\}$, which indicates that the first spell is a left-censored non-employment spell ending in month 1 of reference period 2, the second is a fresh employment spell reported to end in month 4 of reference period 3 , and the third is a fresh non-employment spell which is censored at the end of the sample. (Again in Figure 2 the numbers above the line are the survey months and the numbers below the line are reference period months.) Since the first spell ends in month 1 of the reference period, we assume it is reported correctly. However, the second spell is reported to have ended in month 4 of the third reference period. Given our assumptions the reported history could be true, but there are also three additional possible histories A, B, and C as illustrated in Figure 2. Specifically, the second spell could actually have ended in month 1 of the following reference period, which implies that we would need to reduce the duration of the subsequent (censored) spell by one month. Alternatively, it also could have ended in months 2 or 3 of the following reference period, in which case we would need to shorten the length of the subsequent spell by two or three months respectively.

As we show in our Online Appendix 2, the contribution to the likelihood function for the reported history in Figure 2 is given by 22

${ }^{22}$ Grogger (2004) suggests clustering the spells for the same individual in addition to allowing for personspecific unobserved heterogeneity to obtain robust standard errors. We do not follow this approach since the parameter estimates will not be consistent if there is spell-specific heterogeneity that is not taken into account in estimation. 


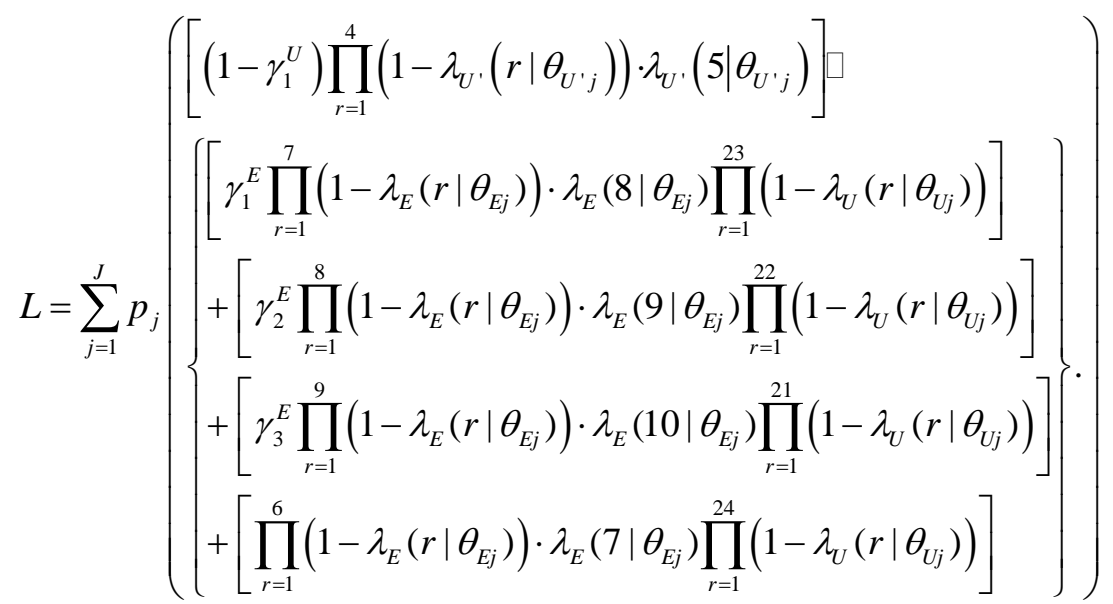

Finally, we also consider an extended model to allow for the possibility that a fraction of the sample never misreports. Specifically, we assume that there are two types of people: type A individuals who always truthfully report their employment histories, and type B individuals who misreport in the way described in Section 4.2 above. Type A people comprise a fraction $P_{A}$ of the population, but of course we cannot discern types in our sample. If an individual is a type A person, she will have the standard multiple-state, multiple-spell likelihood function, see e.g. Eberwein, Ham and LaLonde (1997). If she is a type B person, her likelihood would be the appropriate seam bias likelihood such as (4.12) above. Since we do not know what type of person each individual is, a representative individual's contribution to the likelihood function is

$$
L(\cdot)=P_{A} L^{A}(\cdot)+\left(1-P_{A}\right) L^{B}(\cdot) .
$$

Maximizing the log likelihood based on (4.13) involves estimating only one additional parameter, $P_{A} .23$

For both of our models (represented in (4.12) and (4.13)), we consider two alternatives: i) the misreporting probabilities $\left(\gamma^{\prime} s\right.$ and $\left.P_{A}\right)$ are constant for the whole sample; and ii) the misreporting probabilities $\left(\gamma^{\prime} s\right.$ and $\left.P_{A}\right)$ vary by individual demographics taking the form of equation (4.11). For both $\gamma^{\prime} s$ and $P_{A}$, we find only the race variable has a statistically significant effect on the misreporting probabilities.

\footnotetext{
${ }^{23}$ Care must be exercised if one wants to test the null hypothesis $P_{A}=1$, both because it is on the boundary of the parameter space, and because the misreporting parameters $\gamma^{\prime} s$ are not identified under this null hypothesis (Davies 1987). Fortunately the estimate of $P_{A}$ is quite far from 1 in our case.
} 


\subsection{Using Aggregated Data to Consider Additional Misclassification Schemes}

Of course, there is the possibility that the transitions are misclassified in a way that differs from the scenarios considered above. Here we consider several other possibilities which we argue can be rejected based on aggregates of our micro data. The first possibility we consider is: some of the month 1 transitions are pushed into month 2, some of the month 2 transitions are pushed into

month 3, and some of the month 3 transitions are pushed into month 4 , but none of the month 4 transitions are pushed into the next reference period (because it is the last month in the reference period). If $50 \%$ of the transitions in months 1,2 and 3 are pushed to the next month, then we would see $12.5 \%$ of the transitions in month $1,25 \%$ in month $2,25 \%$ in month 3 , and $37.5 \%$ in month 4 . Alternatively, suppose $75 \%$ of the transitions get pushed out of months 1,2, and 3 . Then we would see $6.25 \%$ of the transitions in month 1, 25\% in month 2, 25\% in month 3, and $43.75 \%$ in month 4 . In either case, month 1 should have a considerably smaller proportion of the transitions than months 2 and 3, and month 4 should have a considerably larger proportion of the transitions than months 2 and 3. However, in our data, months 1, 2, 3, and 4 have $16.57 \%, 19.08 \%, 18.49 \%$, and $45.86 \%$ of the employment/non-employment transitions respectively, which is clearly inconsistent with this alternative model. (Note that our assumptions in Section 4.2 are consistent with this pattern).

Secondly, we consider the possibility that some of the transitions in month 1 of the reference period $l+1$ are pushed back into month 4 of reference period $l$. (Recall that month 1 of the reference period $l+1$ is the interview month for reference period $l$.) If this is the only source of misclassification, then the pattern should be similar to the scheme above: about $25 \%$ of the observed transitions are reported in months 2 and 3, a smaller proportion of transactions are reported in month 1 , and a larger proportion in month 4 . This model would also be rejected by the summary statistics presented in the previous paragraph.

A third possible explanation is that individuals may forget about a fraction of very short spells starting in reference period months 1,2 and 3. In other words, the number of transitions in month 4 is accurately reported, but the numbers in months 1,2 and 3 are under-reported. It is difficult to address the suggestion that individuals forget about some short spells starting in months 1 , 2 and 3 without access to linked administrative data, and certainly this explanation is consistent with the aggregate data reported above. However, we can examine this explanation in another way. We know from administrative data that short spells are much more frequent in employment duration than in welfare duration for the disadvantaged single mothers we study. Thus if we compare the transitions in months 1, 2, 3 and 4 for employment duration data and welfare duration data we would expect to see a larger fraction of transitions in month 4 for the employment data if this explanation is correct. However, we find that $52.7 \%$ of all transitions out of employment were reported to have 
occurred in month 4 , while $62.7 \%$ of all transitions out of welfare were reported to have occurred in month 4, casting doubt on this explanation.

\section{Empirical Results}

\subsection{Hazard Function Estimates from Four Seam Bias Correction Models}

Tables 2A, 2B, and 2C present estimates of the parameters of the hazard functions for four models. The first and second models are the seam bias corrections described in section 4.4 when the misreporting probabilities are constant across individuals (constant misreporting probability model hereafter) and variable across individuals (variable misreporting probability model hereafter) respectively. The third model consists of adding a month 4 (last month of any reference period) dummy to the model (last month dummy model hereafter). The last model uses month 4 data only (last month data model hereafter). Estimates from the last month dummy and last month data models allow us to compare our approach with those that are currently used. All models are estimated with unobserved heterogeneity. We let the data choose the number of support points for the unobserved heterogeneity (as specified in Section 4.4) and the best fitting polynomials (in logarithms) for duration dependence according to the Schwartz criterion for each model, as suggested by Ham, Svejnar and Terrell (1998) and Baker and Melino (2000); this helps to avoid numerical instability problems that come from over-fitting the data. Although we do not focus on the duration dependence and unobserved heterogeneity distribution estimates, they affect our policy experiments, in which we examine the effect of changes in several different variables on the expected duration of a spell and the fraction of time spent in employment.

Tables 2A and 2B contain the hazard estimates for left-censored spells and fresh spells respectively. We believe the parameters of the hazard coefficients are of substantial interest since the employment dynamics of women with low levels of schooling have received much less attention in the literature than the welfare dynamics, despite their importance for determining which families will be in poverty. Table $2 \mathrm{C}$ reports the misreporting probabilities for our seam bias correction models. ${ }^{24}$

Our explanatory variables include a relatively standard mix of policy and demographic variables, except that we also use the minimum wage as an explanatory variable. The hazard is parameterized such that a negative coefficient implies that the hazard decreases if the explanatory variable increases (see equation 4.5). Considering first our seam bias correction estimates with respect to left-censored non-employment spells in the first two columns of Table $2 \mathrm{~A}$, we see that higher

\footnotetext{
${ }^{24}$ Note that unlike the standard case, the log-likelihood function of our seam bias correction models does not become additively separable in the different types of spells even if we ignore unobserved heterogeneity, or restrict the unobserved heterogeneity to be independent across spell type, because we still must allow for seam bias.
} 
welfare benefits, a higher unemployment rate, being African American or Hispanic, being older, having never been married, having more children under six years of age, and having a disability all significantly lower the probability (in a partial correlation sense) that a woman leaves a left-censored non-employment spell. The minimum wage and the implementation of welfare waiver policies (sticks and carrots) at the state level have no significant effect on left-censored non-employment duration. On the other hand, having twelve years of schooling (as opposed to less schooling) significantly increases the probability of leaving such a spell. In terms of left-censored employment spells (Table 2A, columns 5 and 6), we see that higher welfare benefits, having twelve years of schooling, and being older are associated with significantly longer left-censored employment spells. The sign for the welfare benefits variable is puzzling, but we will see in Table $3 \mathrm{~A}$ (upper right panel) that the effects of increasing this benefits variable by $10 \%$ on the expected duration of left-censored employment spells are quite small and statistically insignificant for both the constant and variable misreporting probability models. Being Hispanic, never having been married, having more children under age six, having a disability, or having missing disability status are associated with significantly shorter leftcensored employment spells. Again the minimum wage and the two welfare waiver variables have no significant effects.

Table $2 \mathrm{~B}$ reports hazard estimates for fresh spells. The fact that we have substantially fewer fresh employment and non-employment spells (see Table 1 for the number of spells) leads to fewer variables being statistically significant. For the fresh non-employment spells (columns 1 and 2), facing a higher unemployment rate, being African American, having more children under age eighteen, having more children under age six, having a disability or having missing disability status decreases the hazard rate for leaving a fresh non-employment spell. Being offered a "carrot" to leave welfare significantly reduces the length of a fresh non-employment spell, as does having twelve years of schooling. Finally, when considering fresh employment spells (columns 5 and 6), the exit rate from these spells significantly decreases with an increase in the minimum wage, having twelve years of schooling and being older. On the other hand, an increase in welfare benefits, higher unemployment rate, and having a disability or missing disability status increase the exit rate from a fresh employment spell. For both constant and variable misreporting probability models, the Schwartz criterion indicates that two support points for unobserved heterogeneity, a linear form (in the logarithm of spell duration) of duration dependence for left-censored spells and a quadratic form (in the logarithm of spell duration) of duration dependence for fresh spells are appropriate.

In the constant and variable misreporting probability models, the unemployment rate coefficients suggest that both left-censored and fresh non-employment durations increase with the overall unemployment rate. Further, as in Elsby, Michaels, and Solon (2009), the probability of 
leaving a fresh employment spell increases with the overall unemployment rate, but as in Shimer (2005a, 2005b), the probability of leaving a left-censored employment spell is not affected by the business cycle.

Finally, we discuss the estimated misreporting probabilities from both of our models as presented in Table 2C. For the constant misreporting probability model, the misreporting probabilities for employment spells are re-parameterized as $\gamma_{k}^{E}=\frac{1}{1+\exp \left(-\alpha_{k}^{E}\right)} k=1,2,3$ to constrain the probabilities to be between 0 and 1. For the variable misreporting probability model, the misreporting probabilities for employment spells are parameterized as in equation (4.11). We use analogous specifications for non-employment spells. Note that given the above re-parameterization, an estimated $\alpha_{k}^{E}$ that is not significantly different from zero implies an estimated $\gamma_{k}^{E}$ close to 0.5. In the variable misreporting model, we find that race is the only demographic variable that significantly affects misreporting behavior. Panel A of Table 2C reports parameter estimates of $\alpha$ 's and Panel B reports calculated misreporting probabilities according to the estimates in Panel A. Standard errors in Panel B are calculated using the delta method. All of the misreporting probabilities are statistically and economically significant. In general, the misreporting probabilities are larger for the employment spells than for the non-employment spells. Another interesting pattern is that the probabilities of misreporting are descending from month 1 through month 3 . This pattern indicates that among all transitions occurring in months 1,2 and 3, the longer the time distance between the transition and the interview, the more likely it is that the respondent heaps that transition into the previous month 4 . (Recall that interviews were conducted in month 1 of the following reference period, thus month 1 transitions occurred furthest from the interview time). According to the constant misreporting probability model, $56.8 \%, 45.6 \%$ and $44.1 \%$ of month 1, 2, and 3 transitions out of non-employment spells, respectively, have been shifted to month 4 ; while $72.9 \%, 60.1 \%$, and $58.5 \%$ of month 1,2 , and 3 transitions out of employment spells, respectively, have been shifted to month $4 .{ }^{25}$ African Americans and Hispanics are more likely to misreport by about 7 to 8 percentage points for nonemployment spells and by about 7 to 10 percentage points for employment spells.

Interestingly, while we find significantly lower misreporting probabilities among Whites, the coefficients and significance levels are remarkably similar for the estimates of the parameters of the

\footnotetext{
${ }^{25}$ We do not formally test the null hypothesis that all the misreporting probabilities are zero using a likelihood ratio test for two reasons. First, it is clear from the aggregate data that a model that does not account for seam bias in some way will fit the data poorly; i.e. the null hypothesis does not describe an interesting model. Secondly, if we were to test formally this null hypothesis, we would have to take into account that we are testing whether parameters are on the boundaries of the parameter space (in six dimensions), i.e. we are in a nonstandard testing situation. Given the size of the estimated misreporting probabilities, testing whether they are zero does not seem very interesting and thus would not warrant dealing with the nonstandard testing issues.
} 
hazard functions from the two (constant versus variable) misreporting models in Tables 2A and 2B. For the sole purpose of correcting for seam bias, our results suggest that a constant misreporting probability model will be sufficient. However, if a researcher is also interested in investigating misreporting behavior, a richer model allowing misreporting probability to vary with individual characteristics will be needed.

There are differences among the estimates based on our seam bias correction models and the estimates from the other two approaches in the literature, the last month dummy model and the last month data model, in terms of point estimates and standard errors. Note that the magnitudes of the coefficients of the last month data model are not directly comparable with our seam bias correction models and the last month dummy variable model. For the seam bias correction models and the last month dummy variable model, the time unit for the discrete hazard is one month, while for the last month data model, the time unit for the discrete hazard is four months (refer to Section 3 for details of the spell construction for the last month data model). However, here we compare signs as well as statistical significance across the four models, and then in the next section we compare the effect of changing explanatory variables on the expected durations of the individual spells for the four models, which takes into account different time intervals for the different hazards.

Since empirical researchers typically focus only on estimates that are statistically significant, we compare differences in the significant coefficients produced by each model. First considering the left-censored non-employment spells in Table 2A (left panel), our seam bias approach finds significant effects of being African American, while this is not true for the simpler models. Further, all models except the last month data model find a significant effect of being Hispanic. On the other hand, the simpler models find a significant effect of having disability status missing, but this is not true for our seam bias models. Considering the estimates for the left-censored employment spells (right panel), the seam bias models find a significant effect for welfare benefits but the simpler models do not; the opposite is true for the unemployment rate and being African American. Finally while the seam bias models and the last month dummy variable model show significant effects for both the number of children less than 6 years old and the disability variable missing, this is not true for the last month data model. As for the age of the youngest child variable, only the last month data model finds a significant effect.

Considering the fresh non-employment spells (Table 2B, left panel), our seam bias models and the last month dummy variable model find significant roles for the unemployment rate, the welfare waiver carrot variable and being African American, while this is not true for the last month data approach. Welfare benefits are only significant using the last month dummy variable model, and the number of children less than 18 years is only significant for our seam bias models. Finally, 
considering the fresh employment spells (Table $2 \mathrm{~B}$, right panel), we note that only our seam bias models find significant roles for the unemployment rate, the minimum wage and the disability variable missing, and only the last month data model finds a significant effect of being African American and having never been married.

\subsection{Expected Durations and the Effect of Changing an Explanatory Variable on Expected Durations}

To look at estimated effects which are comparable across the four models we first calculate expected durations and the effects of changing explanatory variables on the expected duration of each type of spell. Conditional on the unobserved heterogeneity, the probability that a spell of type $j$, where $j=U^{\prime}, U, E$ ', $E$ (as defined in Section 3), lasts longer than $t-1$ months is given by the survivor function

$$
S_{j}\left(t-1 \mid \theta_{j}\right)=\prod_{\tau=1}^{t-1}\left[1-\lambda_{j}\left(\tau \mid \theta_{j}\right)\right] .
$$

The density function for a spell of type $j$ that lasts $t$ months is given by

$$
f_{j}\left(t \mid \theta_{j}\right)=\lambda_{j}\left(t \mid \theta_{j}\right) S_{j}\left(t-1 \mid \theta_{j}\right)
$$

The expected duration for a spell of type $j$ is given by

$$
E D_{j}=\sum_{j=1}^{J} \sum_{t=1}^{\infty} t \cdot f_{j}\left(t \mid \theta_{j}\right) \cdot p_{j}
$$

Since there is no guarantee this expected duration will be finite, we instead calculate a truncated mean for each type of spell as follows:

$$
E D_{j}=\sum_{j}^{J}\left[\sum_{t=1}^{T^{*}} t \cdot f_{j}\left(t \mid \theta_{j}\right)+S\left(T^{*} \mid \theta_{j}\right) \cdot T^{*}\right] \cdot p_{j} .
$$

We choose $T^{*}=60 .{ }^{26}$ We calculate the expected durations for each individual and take the sample average. To test whether the out-of-sample durations are having a disproportionate impact on estimated expected duration, we also follow Eberwein, Ham and LaLonde (2002) and freeze the hazard function for durations longer than 15 months at 15 months for fresh spells and freeze the hazard function for durations longer than 25 months at 25 months for left-censored spells. We find that freezing the hazard function does not make a noticeable difference in estimated expected durations. We also estimate the effect on expected duration if we change an explanatory variable for the four models. We set an explanatory variable at two different levels and calculate the

\footnotetext{
26 The longest panel in our data lasts 40 months.
} 
corresponding expected durations; the difference between the two expected durations represents the effect of changing that particular explanatory variable on expected duration. Standard errors for expected durations and effects of changes in explanatory variables on expected duration are calculated using the delta method.

Our estimated expected durations and the effects which changing explanatory variables have on expected duration are presented in Tables $3 \mathrm{~A}$ and $3 \mathrm{~B}$. Note that when we calculate the expected duration for the last month data model, we have taken into consideration that this model uses a fourmonth hazard (compared with the other models' monthly hazards), while when we calculate the expected duration for the last month dummy model, we add one-quarter of the last month dummy coefficient to each support point of unobserved heterogeneity. The first row of Table $3 \mathrm{~A}$ reports the expected durations (without freezing the duration function for longer spells). The expected durations for left-censored spells, both employment and non-employment, are comparable across the four models, with those from the last month dummy variable model being slightly shorter. For fresh spells, the expected durations are quite similar between the constant and variable misreporting probability models as both are about 11 to 12 months. However the estimates from the last month data model are much larger: the expected fresh non-employment duration is about 23 months and the expected fresh employment duration is about 33 months. The estimates from the last month dummy variable model are between those from our misreporting probability models and the last month data model, with the expected fresh non-employment duration being about 16 months and the expected fresh employment duration being about 28 months. The longer expected durations for fresh spells estimated from the last month data model can at least be partly explained by the loss of short fresh spells (as discussed in Section 3).

The rest of Table $3 \mathrm{~A}$ presents the effects of changes in welfare policy variables or macroeconomic conditions on expected durations. We first discuss the effects for left-censored nonemployment spells (top left panel). Increasing state maximum welfare benefits by $10 \%$ lengthens leftcensored non-employment spells by around half a month in all models, although this effect is not statistically significant in the last month data model. We do not find statistically significant effects of implementing welfare carrot or stick waivers; moreover there is not a statistically significant effect of increasing the minimum wage by $10 \%$. If the state overall unemployment rate increases by $25 \%$ (i.e. from $6 \%$ to $7.5 \%$ ), the expected duration of left-censored non-employment spells increases by about 1.4 to 1.8 months. None of the above variables have a precisely estimated effect in any model for left-censored employment spells (top right panel).

Next we discuss the estimated effects for fresh non-employment spells (bottom left panel). Increasing the state maximum welfare benefit by $10 \%$ has a very small positive effect, and it is 
statistically significant only for the last month dummy variable model. Implementing a carrot waiver policy reduces the expected duration by 3 to 4 months, but this effect is not statistically significant for the last month data model. Neither implementing a stick waiver policy nor increasing the minimum wage has a statistically distinguishable effect on the expected duration. If the state unemployment rate increases by $25 \%$, the expected duration increases, in this case by about 0.8 to 1.2 months. This effect is not significant for the last month data model.

Lastly we discuss the effects on fresh employment spells (bottom right panel). The constant and variable misreporting probability models and the last month dummy model estimate significant effects of increasing the state maximum welfare benefits by $10 \%$, reducing the expected duration by 0.2 to 0.4 months. None of the four models precisely estimate any effects of the two welfare policies, carrot and stick waivers. Only the constant and variable misreporting probability models estimate significant effects of increasing the minimum wage by $10 \%$, with the change increasing the expected duration by about 1.5 months. Finally, the constant and variable misreporting probability models predict that increasing the unemployment rate by $25 \%$ reduces the expected duration by about 0.7 of a month while this effect is statistically insignificant in the other two models.

Table 3B presents the effects of changing individual characteristics on expected durations. Compared with the effects presented in Table $3 \mathrm{~A}$, in general these effects exhibit larger discrepancies between models in terms of both magnitude and statistical significance. Again we first discuss the effects for the left-censored non-employment spells (top left panel). Being older (age 35 versus age 25) makes the expected duration of these spells significantly longer. This effect is about 7.5 months according to the two misreporting probability models, about 6.3 months according to the last month dummy model, and about 3.6 months according to the last month data model. Those who have a full 12 years of education have an expected duration 5 to 7 months shorter than those with less education, and the last month data model predicts the largest effect. Only the two misreporting probability models estimate significant effects of being an African American (versus being White), lengthening the expected duration by about 2.5 months. The two misreporting probability models and the last month dummy variable model estimate that being Hispanic (versus White) makes the expected duration about 2 to 3 months longer. (Note that all of these effects are only significant at the $10 \%$ level.) All four models estimate a positive and significant effect of having one child under six years old relative to having none, and this effect on expected duration is about 4 to 5 months.

We discuss the effects on left-censored employment spells in Table 3B (top right panel). All models predict that growing older (again 35 versus 25) makes the expected duration 3 to 5 months longer, with the estimate from the last month data model being the smallest. Having 12 years of education versus having less education increases the expected duration by 7 to 9 months. The two 
misreporting probability models estimate the effect of being African American to be small and insignificant while the other two models estimate that this reduces expected employment duration by a statistically significant 5 months. The two misreporting probability models and the last month dummy model variable estimate being Hispanic as shortening the expected duration by about 2.6 months, while the last month data model does not detect a significant effect. Except for the last month data model, all of the other three models predict that having one child less than 6 years old reduces the expected duration by approximately 2 months.

Turning to the fresh non-employment spells in Table 3B (bottom left panel), none of the models predict that age has a significant effect. The two misreporting probability models estimate the effect of having more education to be about 2 months, while the last month data model predicts this effect to be almost 4 months. The estimated education effect from the last month dummy variable model is about 3 months. Among the four models, the last month dummy variable model predicts the largest effect of being African American, with the expected duration being about 4.6 months longer. The two misreporting probability models predict this effect to be about 1.8 months, while the effect in the last month data model is statistically insignificant. None of the models show a significant effect of being Hispanic. The four models predict quite different effects of having one child less than six years old. According to the two misreporting probability models, this effect is about 1.2 months, while it is about 2 months according to the last month dummy variable model and about 3 months according to the last month data model.

Lastly we discuss the effects of changing the explanatory variables on the fresh employment spells in Table 3B (bottom right panel). The two misreporting probability models estimate a small effect of age 35 versus age 25, with an expected duration of approximately 1 additional month. However, the other two models predict this effect to be much larger: more than 5 months. The last month dummy and last month data models also predict the effect on expected duration of having 12 years of education relative to less schooling (about 6 and 5 months, respectively,) to be larger than our misreporting probability models predict (about 3 months). Only the last month data model predicts a significant effect of being African American, with expected duration being about 3 months shorter. None of the models predict significant effects of being Hispanic or having one child less than 6 years old (versus none).

Tables $3 \mathrm{~A}$ and $3 \mathrm{~B}$ show that there are important differences between our seam bias estimates and estimates from the last month dummy variable model, and very important differences between our seam bias estimates and those obtained using the last month data. As discussed in Section 3, when considering completed spells, shifting from monthly data to the last month data yields a loss of about $20 \%$ of left-censored spells and about $50 \%$ of fresh spells. The substantial 
discrepancies in both magnitude and statistical significance between the estimates from our seam bias correction models and those from the last month data model are likely to be due at least partially to this major shift in data structure. While the last month dummy model often produces results that are closer to the results from the seam bias correction models than the results of the last month data model, the fact that important differences remain indicates that the last month dummy model is not a totally adequate solution.

\subsection{Results from the Extended Model with a Fraction of Individuals Accurately Reporting Their Employment Histories}

To further explore the misreporting behavior, we estimate an extended model as specified in equation (4.13) of Section 4.4 where some individuals never misreport. This model involves one additional parameter $P_{A}$, the fraction of individuals who always report accurately. In addition, we also estimate a version of this richer model allowing $P_{A}$ and the six misreporting parameters to vary with ethnicity. Our Online Appendix Table A3 presents the estimated hazard coefficients from the constant and variable probability versions of this richer model, while the misreporting estimates are reported in Table 4. The estimated hazard coefficients and standard errors are remarkably similar between the two models, and indeed they are very close to the results for the hazard coefficients from the constant and variable probability models discussed in Section 5.1 above. The last row of Table 4 Panel B reports the fraction of individuals reporting accurately. The constant probability model estimates that fraction to be $15.5 \%$ with a $95 \%$ confidence interval of approximately $(9.6 \%$, $21.4 \%$ ). Interestingly, the race effects are no longer statistically significant in this richer model. These results reinforce our earlier conclusion that a simple constant misreporting probability model will serve the purpose of estimating the parameters of the hazard functions, but if a researcher is also interested in misreporting behavior per se, increasing the model complexity provides added valuable information about misreporting behavior. ${ }^{27}$

\subsection{Simulation Results for the Effects of Changing an Explanatory Variable on the Fraction of Time Spent Employed}

Estimating the effect of changing an explanatory variable on the fraction of time that an individual is employed is another useful exercise for policy purposes. We use simulations to predict the fraction of time spent in employment over 3-year (short-run), 6-year (medium-run) and 10-year

\footnotetext{
${ }^{27}$ We do not test the null hypothesis that the fraction of individuals who always report truthfully is zero, since again we would have to take into account that we are testing whether a parameter is on the boundary of the parameter space.
} 
(long-run) horizons, as well as to examine how these fractions change with macro and public policy variables. We only use our simple constant misreporting probability model (presented in Tables $2 \mathrm{~A}$ and $2 \mathrm{~B}$ ) for the simulation, since as noted above, the hazard estimates are very similar across our misreporting models. We simulate an employment/non-employment history for each individual over a particular time horizon and then calculate the sample fraction of time employed based on simulated individual histories. Note that the simulated fractions depend on the parameter estimates for all four types of spells (but not on the misreporting probabilities). Because the simulations are discontinuous functions of the parameter estimates, we cannot use the delta method to obtain standard errors; instead to obtain standard errors we follow Ham and Woutersen (2009) and sample from the asymptotic distribution of the parameters. We outline our simulation procedure in the following steps:

1. For each individual, we simulate her 10 -year monthly employment history by unobserved heterogeneity type.$^{28}$ For example, if the model indicates that there are two points of support for unobserved heterogeneity ( $J=2$ in the specification described in Section 4.4), we simulate two employment histories for each individual conditional on belonging to each of the two types.

1.1 The starting point of an employment history is determined by the data. If a person was in a left-censored non-employment spell at the beginning of the sample, her simulated employment history will start with a left-censored non-employment spell.

1.2 From the starting month, an individual monthly hazard rate is calculated based on unobserved heterogeneity type, observed heterogeneity (individual means over the sample period are used), spell type (e.g. left-censored employment spell) and spell length. ${ }^{29}$

1.3 A uniform random number is drawn to compare with the calculated hazard and determine whether the individual exits into the next spell. Steps 1.2 and 1.3 are repeated for 120 months for each individual and unobserved heterogeneity type. If individual $i(i=1, N)$ of unobserved type $j(j=1, J)$ is employed in month $t(t=1,120)$ then $E_{i j}^{t}=1$, otherwise $E_{i j}^{t}=0$.

1.4 For individual $i$, we average simulated histories across unobserved heterogeneity type according to the estimated probabilities $p_{j}$ to yield weighted employment history

\footnotetext{
28 Our simulation results (including standard errors) are insensitive to increasing the number of simulations per person.

${ }_{29}$ Again we face the issue of what to do with the duration dependence once we get out of sample. We choose to freeze the hazard function for durations longer than 15 months at 15 months for fresh spells and freeze the hazard function for durations longer than 25 months at 25 months for left-censored spells.
} 


$$
E_{i}^{t}=\sum_{j=1}^{J} p_{j} E_{i j}^{t}
$$

2. We average the simulated histories over the sample and over the first 36,72 , or all 120 months to estimate 3-year, 6-year, and 10-year employment fractions

$$
\begin{aligned}
& E R_{3 y r}=\frac{\sum_{i=1}^{N} \sum_{t=1}^{36} E_{i}^{t}}{36 \cdot N} \\
& E R_{6 y r}=\frac{\sum_{i=1}^{N} \sum_{t=1}^{72} E_{i}^{t}}{72 \cdot N} \\
& E R_{10 y r}=\frac{\sum_{i=1}^{N} \sum_{t=1}^{120} E_{i}^{t}}{120 \cdot N}
\end{aligned}
$$

3. We simulate standard errors for estimates of fractions as follows:

3.1 We assume generate (1000) alternative values of the parameters using the estimated asymptotic Normal distribution.

3.2 We repeat steps 1 to 2 for each set of parameter values to get new estimates of $E R_{3 y r}, E R_{6 y r}$ and $E R_{10 y r}$.

3.3 We construct standard errors for all three fractions using the 1000 estimates of $E R_{3 y r}, E R_{6 y r}$ and $E R_{10 y r}$.

4. To predict the effect of changing one of the macro or policy variables on the above three fractions, we follow the previous steps by setting the variable of interest at different levels for each person and then taking the difference in estimated fractions. For example to estimate the effect of implementing positive incentives to leave welfare (carrot waiver policy), we first set the carrot waiver dummy to 1 for each person (i.e. carrot waivers are implemented in all states) to calculate $E R_{3 y r}^{1}, E R_{6 y r}^{1}$ and $E R_{10 y r}^{1}$; then set the carrot waiver dummy to 0 for each person (i.e. carrot waivers are not implemented in any state) to calculate $E R_{3 y r}^{0}, E R_{6 y r}^{0}$ and $E R_{10 y r}^{0}$. $E R_{3 y r}^{1}-E R_{3 y r}^{0}, E R_{6 y r}^{1}-E R_{6 y r}^{0}$ and $E R_{10 y r}^{1}-E R_{10 y r}^{0}$ are the estimated effects of implementing a carrot waiver policy.

5. We estimate standard errors for the effects of changing macro or public policy variables following step 3 at each level of those variables.

Table 5 presents our simulation results. The first row contains the estimated employment fractions for 3-year, 6-year and 10-year periods, respectively. The predicted employment fractions are 
only around $44 \%$ for our sample of single mothers with 12 years of education or less. The rest of the table presents how those employment fractions would change with welfare policies and general macroeconomic conditions. Increasing the state maximum monthly welfare benefits by $10 \%$ reduces the predicted fraction of time employed by 0.2 to 0.3 percentage points. This effect is statistically significant but relatively small. Implementing a carrot waiver policy increases the predicted fraction of time employed by 3.6 to 4.2 percentage points, although these effects are only significant at the $10 \%$ level. Implementing a stick waiver policy has no effect on the predicted fraction of time employed. We find that increasing the minimum wage by $10 \%$ also has essentially no effect on the employment fraction. Finally if the overall state unemployment rate increases by $25 \%$, the fraction of time employed is predicted to fall by 1.4 to 1.8 percentage points.

\section{Summary and Conclusions}

Transitions into and out of employment for disadvantaged single mothers are of crucial importance to policymakers, as they determine unemployment rates, poverty rates and the overall well-being of many low-income families. In this paper we use the SIPP to estimate monthly transition rates into and out of employment for these women. Such employment dynamics have been relatively understudied in the literature, given the substantial policy interest paid to less-educated single mothers and their children and the emphasis that policy makers have placed on increasing employment durations as a means of increasing on-the-job human capital for disadvantaged women.

Seam bias is an important problem that faces any researcher estimating transition rates from the SIPP. In this study we propose a parametric approach to address this issue. Specifically, we develop a monthly discrete time duration model with parameters representing the propensity to underreport transitions in the first three months of a reference period. We first assume that misreporting probabilities are constant across individuals, and then consider a second case where we allow the misreporting probabilities to depend on demographic variables. We show that both models are identified without restricting the form of the duration dependence as long as we assume that the misreporting probabilities are the same for left-censored and fresh employment (non-employment) spells. We also estimate the hazard functions using two approaches found in previous literature: using only the last month data and putting in a dummy variable in the hazard for month 4 and then adjusting the constant using the estimated coefficient on this dummy variable. We find that our estimates of the parameters of the hazard functions from our seam bias models are not sensitive to allowing the misreporting probabilities to depend on race. However, we do find that there are important differences between our seam bias estimates and those obtained from the last month dummy variable model, and very important differences between our seam bias estimates and those 
obtained using only last month data. Our estimates of the hazard functions are also robust to allowing for the possibility that a certain fraction of individuals never misreport. We conclude that allowing for richer models of misreporting are important for understanding misreporting behavior, but not for estimating the hazard functions.

In considering the issue of whether we have the "right" model of misreporting, we would make the following points: First, we estimate four misreporting models: i) our main model with constant misreporting probabilities, ii) our main model in which the misreporting probabilities are allowed to vary with the characteristics of the individual, iii) the richer model in which some respondents truthfully report while others misreport with constant misreporting probabilities, and iv) the richer model still in which the probability of a respondent always truthfully reporting and the misreporting probabilities vary with ethnicity. As noted above, all four of these models produce very similar estimates of the parameters of the hazard functions. Second, the telescoping behavior assumed in our misreporting models is exactly the type of behavior that the 2004 revision of the SIPP aimed to minimize. Third, a previous study that compared survey data against administrative records (Goudreau, Oberheu and Vaughan 1984) also suggests that our assumed misreporting behavior is the most common source of discrepancies between survey data and administrative records. Fourth, our results on higher misreporting by minorities mirror the previous findings of Kalton and Miller (1991) and Black, Sanders, and Taylor (2003), who investigated how different demographic factors affect individuals' reporting of Social Security income amounts and education, respectively. Finally, we also consider three alternative models of misreporting and are able to reject them based on aggregates of our micro data. Thus we have considered a wide range of misreporting models; moreover, our choice of these models and our results are supported by previous research.

\section{References}

Aaronson, S., and J. Pingle (2006): "The Employment Dynamics of Single Mothers Following TANF." Mimeo, Board of Governors of the Federal Reserve System.

Acs, G., K. R. Phillips, and S. Nelson (2003): "The Road Not Taken? Changes in Welfare Entry During the 1990s." Urban Institute Discussion Paper 03-03.

Ashenfelter, O., and D. Card (1981): "Using Longitudinal Data to Estimate the Employment Effects of the Minimum Wage." Centre for Labour Economics, London School of Economics Discussion Paper.

Baker, M., and A. Melino (2000): "Duration Dependence and Nonparametric Heterogeneity: A Monte Carlo Study." Journal of Econometrics, 96(2), 357-393.

Black, D., S. Sanders, and L. Taylor (2003): "Measurement of Higher Education in the Census and Current Population Survey." Journal of the American Statistical Association, 98(463), 545-554.

Blank, R., and P. Ruggles (1996): "When Do Women Use Aid to Families with Dependent Children and Food Stamps? The Dynamics of Eligibility Versus Participation." Journal of Human Resources, Winter, 31(1), 57-89. 
Campolieti, M., T. Fang, and M. Gunderson (2005): "Minimum Wage Impacts on Youth Employment Transitions, 1993-1999." Canadian Journal of Economics, 38(1), 81-104.

Chakravarty, S., and A. Sarkar (1999): "Liquidity in U.S. Fixed Income Markets: A Comparison of the Bid-Ask Spread in Corporate, Government and Municipal Bond Markets." Mimeo, Purdue University.

Currie, J., and B. C. Fallick (1996): "The Minimum Wage and the Employment of Youth: Evidence from the NLSY." Journal of Human Resources, Spring, 31(2), 404-428.

Czajka, J. (1983): "Subannual Income Estimation" in Technical, Conceptual and Administrative Lessons of the Income Survey Development Program (ISDP), ed. by M. David, New York: Social Science Research Council, 87-97.

Davies, R. B. (1987): "Hypothesis Testing when a Nuisance Parameter is Present Only under the Alternative." Biometrika, 74(1), 33-43.

Eberwein, C., J. Ham, and R. LaLonde (1997): “The Impact of Being Offered and Receiving Classroom Training on the Employment Histories of Disadvantaged Women: Evidence From Experimental Data." The Review of Economic Studies, 64(4), 655-682.

(2002): “Alternative Methods of Estimating Program Effects in Event History Models." Labour Economics, 9(2), 249-278.

Elbers, C. and G. Ridder (1982): “True and Spurious Duration Dependence: The Identifiability of the Proportional Hazard Model." Review of Economic Studies, 49(3), 403-409.

Elsby, M., R. Michaels, and G. Solon (2009): "The Ins and Outs of Cyclical Unemployment." American Economic Journal: Macroeconomics, 1(1), 84-110.

Fitzgerald, J. M. (2004): "Measuring the Impact of Welfare Benefits on Welfare Durations: State Stratified Partial Likelihood and Fixed Effect Approaches." Topics in Economic Analysis \& Policy, 4(1), article 1, http://www.bepress.com/bejeap/topics/vol4/iss1/art1.

Gittleman, M. (2001): "Declining Caseloads: What Do the Dynamics of Welfare Participation Reveal?” Industrial Relations, 40(4), 537-570.

Goudreau, K., H. Oberheu, and D. Vaughan (1984): “An Assessment of the Quality of Survey Reports of Income from the Aid to Families with Dependent Children (AFDC) Program." Journal of Business and Economic Statistics, 2(2), 179-186.

Grogger, J. (2004): "Welfare Transitions in the 1990s: The Economy, Welfare Policy, and the EITC." Journal of Policy Analysis and Management, 23(4), 671-695.

Ham, J. and R. LaLonde (1996): "The Effect of Sample Selection and Initial Conditions in Duration Models: Evidence from Experimental Data on Training." Econometrica, 64(1), 175-205.

Ham, J. and L. Shore-Sheppard (2005a): "Did Expanding Medicaid Affect Welfare Participation?" Industrial and Labor Relations Review, 58(3), 452-470.

(2005b): "The Effect of Medicaid Expansions for Low-Income Children on Medicaid Participation and Private Insurance Coverage: Evidence from the SIPP." Journal of Public Economics, 89(1), 57-83.

Ham, J., J. Svejnar, and K. Terrell (1998): "Unemployment, the Social Safety Net and Efficiency during the Transition: Evidence from Micro Data on Czech and Slovak Men." American Economic Review, 88(5), 1117- 1142.

Ham, J., and T. Woutersen (2009): "Calculating Standard Errors for Discontinuous Functions of Parameter Estimates." Mimeo, Johns Hopkins.

Hamersma, S. (2006): "Why Don't Eligible Firms Claim Hiring Subsidies? The Role of Job Duration." Mimeo, University of Florida. 
Heckman, J. J., and B. Singer (1984a): "Econometric Duration Analysis." Journal of Econometrics, 24(12), 63-132.

(1984b): "A Method for Minimizing the Impact of Distributional Assumptions in Econometric Models for Duration Data.” Econometrica, 52(2), 271-320.

(1984c): “The Identifiability of the Proportional Hazard Model." Review of Economic Studies, 51(2), 231-241.

Hofferth, S. L., S. Stanhope, and K. M. Harris (2002): "Exiting Welfare in the 1990s: Did Public Policy Influence Recipients' Behavior?” Population Research and Policy Review, 21, 433-472.

Honore, B. (1993): "Identification Results for Duration Models with Multiple Spells." Review of Economic Studies, 60(1), 241-246.

Kalton, G., and M. E. Miller (1991): "The Seam Effect with Social Security Income in the Survey of Income and Program Participation." Journal of Official Statistics, 7(2), 235-245.

Lemaitre, G. (1992): "Dealing with the Seam Problem for the Survey of Labour and Income Dynamics." SLID Research Paper Series, No. 92-05. Ottawa: Statistics Canada.

Manski, C. (1994): “Analog Estimation of Econometric Models," in Handbook of Econometrics, Vol. 4, ed. by R. Engle and D. McFadden, Amsterdam: North-Holland, 2559-2582.

Marquis, K. H. and J. C. Moore (1990): "Measurement Errors in the Survey of Income and Program Participation (SIPP) Program Reports." 1990 Annual Research Conference Proceedings, Washington, D.C.: U.S. Bureau of the Census.

McCall, B. P. (1996): "The Identifiability of the Mixed Proportional Hazards Model with TimeVarying Coefficients." Econometric Theory, 12(4), 733-738.

Moore, J. C. (2008): "Seam Bias in the 2004 SIPP Panel: Much Improved, but Much Bias Still Remains." U.S. Census Bureau Statistical Research Division Survey Methodology Research Report Series \#2008-3. Available at http://www.census.gov/srd/papers/pdf/rsm200803.pdf.

Pischke, S. (1995): "Individual Income, Incomplete Information, and Aggregate Consumption." Econometrica, 63(4), 805-840.

Ribar, D. (2005): "Transitions from Welfare and the Employment Prospects of Low-Skill Workers." Southern Economic Journal, 71(3), 514-533.

Rips, L. J., F. G. Conrad, and S. S. Fricker (2003): "Straightening the Seam Effect in Panel Surveys." Public Opinion Quarterly, 67(4), 522-554.

Romeo, C. (2001): "Controlling for Seam Problems in Duration Model Estimates: With Application to the Current Population Survey and the Computer Aided Telephone Interview/Computer Aided Personal Interview Overlap Survey." Journal of Human Resources, 36(3), 467-499.

Ryscavage, P. (1988): "Measuring Spells of Unemployment and Their Outcomes." U. S. Bureau of the Census SIPP Working Paper \#84, (http://www.census.gov/dusd/MAB/wp84.pdf).

Shimer, R. (2005a): Reassessing the Ins and Outs of Unemployment, Mimeo, University of Chicago.

(2005b): "The Cyclicality of Hires, Separations, and Job-to-Job Transitions." Federal Reserve Bank of St. Lonis Review, July-August, 87(4), 493-507.

Sudman S., and N. M. Bradburn (1974): Response Effects in Surveys: A Review and Synthesis. Chicago: Aldine Publishing Co.

Yelowitz, A. (1995): "The Medicaid Notch, Labor Supply, and Welfare Participation: Evidence from Eligibility Expansions." Quarterly Journal of Economics, 110(4), 909-940.

Young, N. (1989): "Wave Seam Effects in the SIPP: Implications for Analysis." U.S. Bureau of the Census, Mimeo. 
Table 1. Characteristics of Employment and Non-employment Spells Single Mothers with a Maximum of Twelve Years of Education

\begin{tabular}{|c|c|c|c|c|}
\hline \multirow[b]{2}{*}{ Panel A: Non-employment spells } & \multicolumn{2}{|c|}{$\begin{array}{l}\text { Left-censored spells } \\
\end{array}$} & \multicolumn{2}{|c|}{ Fresh spells } \\
\hline & Mean & Std Dev & Mean & Std Dev \\
\hline Right censored (\%) & $64.5 \%$ & & $42.6 \%$ & \\
\hline African American & 0.34 & 0.48 & 0.33 & 0.47 \\
\hline Hispanic & 0.23 & 0.42 & 0.17 & 0.38 \\
\hline 12 years of schooling & 0.44 & 0.50 & 0.61 & 0.49 \\
\hline Age & 30.08 & 9.01 & 31.24 & 8.65 \\
\hline Never married & 0.50 & 0.50 & 0.45 & 0.50 \\
\hline \# of children < 18 & 1.98 & 1.19 & 1.72 & 0.97 \\
\hline Age of youngest child & 5.00 & 5.09 & 6.56 & 5.10 \\
\hline \# of children $<6$ & 0.93 & 0.91 & 0.65 & 0.75 \\
\hline Disability (adult or child) & 0.24 & 0.42 & 0.19 & 0.39 \\
\hline Disability variable missing & 0.17 & 0.37 & 0.08 & 0.27 \\
\hline number of spells & 3,528 & & 2,578 & \\
\hline number of individuals & 3,528 & & 1,889 & \\
\hline \multirow[t]{2}{*}{ number of observations: year*individual } & 63,384 & & 18,811 & \\
\hline & \multicolumn{2}{|c|}{ Left-censored spells } & \multicolumn{2}{|c|}{ Fresh spells } \\
\hline Panel B: Employment spells & Mean & Std Dev & Mean & Std Dev \\
\hline Right censored (\%) & $69.9 \%$ & & $47.8 \%$ & \\
\hline African American & 0.26 & 0.44 & 0.32 & 0.47 \\
\hline Hispanic & 0.14 & 0.35 & 0.18 & 0.39 \\
\hline 12 years of schooling & 0.74 & 0.44 & 0.61 & 0.49 \\
\hline Age & 33.99 & 8.49 & 30.86 & 8.58 \\
\hline Never married & 0.27 & 0.45 & 0.45 & 0.50 \\
\hline \# of children $<18$ & 1.55 & 0.86 & 1.78 & 1.02 \\
\hline Age of youngest child & 8.14 & 5.44 & 6.28 & 5.12 \\
\hline \# of children $<6$ & 0.46 & 0.66 & 0.68 & 0.76 \\
\hline Disability (adult or child) & 0.12 & 0.33 & 0.18 & 0.38 \\
\hline Disability variable missing & 0.13 & 0.34 & 0.07 & 0.26 \\
\hline number of spells & 3,826 & & 2,732 & \\
\hline number of individuals & 3,826 & & 2,000 & \\
\hline number of observations: year*individual & 71,613 & & 21,376 & \\
\hline total number of individuals & 7,354 & & & \\
\hline total number of observations & 175,184 & & & \\
\hline
\end{tabular}

Notes:

1. Sample means are from the first month of spells.

2. Summary statistics across spells are not independent in the sense that some individuals show up in both left-censored and fresh spells.

3. The numbers of spells reported in this table include both completed spells and right-censored spells.

4. The total number of individuals in the sample is not the sum of the number of individuals in the four types of spells because some individuals have multiple spells of different types, e.g. a leftcensored non-employment spell followed by a fresh employment spell. 
Table 2A. Duration Models of Employment and Non-employment Spells Single Mothers with a Maximum of Twelve Years of Education - Left-censored Spells

\begin{tabular}{|c|c|c|c|c|c|c|c|c|}
\hline & \multicolumn{4}{|c|}{ Left-censored non-employment spells } & \multicolumn{4}{|c|}{ Left-censored employment spells } \\
\hline & $\begin{array}{c}\text { Constant } \\
\text { Probabilities }\end{array}$ & $\begin{array}{c}\text { Variable } \\
\text { Probabilities }\end{array}$ & $\begin{array}{c}\text { Last Month } \\
\text { Dummy }\end{array}$ & $\begin{array}{c}\text { Last Month } \\
\text { Data }\end{array}$ & $\begin{array}{c}\text { Constant } \\
\text { Probabilities }\end{array}$ & $\begin{array}{c}\text { Variable } \\
\text { Probabilities }\end{array}$ & $\begin{array}{c}\text { Last Month } \\
\text { Dummy }\end{array}$ & $\begin{array}{c}\text { Last Month } \\
\text { Data }\end{array}$ \\
\hline Maximum Welfare Benefit & $\begin{array}{c}-9.985^{* *} \\
(2.386)\end{array}$ & $\begin{array}{c}-9.998^{* *} \\
(2.386)\end{array}$ & $\begin{array}{c}-10.130^{* *} \\
(2.122)\end{array}$ & $\begin{array}{c}-11.918^{* *} \\
(2.392)\end{array}$ & $\begin{array}{c}-7.757^{* *} \\
(2.957)\end{array}$ & $\begin{array}{c}-7.754^{* *} \\
(2.957)\end{array}$ & $\begin{array}{l}-0.756 \\
(2.262)\end{array}$ & $\begin{array}{c}1.561 \\
(2.556)\end{array}$ \\
\hline Unemployment Rate & $\begin{array}{c}-0.0613^{* *} \\
(0.023)\end{array}$ & $\begin{array}{c}-0.061^{* *} \\
(0.023)\end{array}$ & $\begin{array}{c}-0.0742^{* *} \\
(0.021)\end{array}$ & $\begin{array}{c}-0.081^{* *} \\
(0.024)\end{array}$ & $\begin{array}{l}-0.0004 \\
(0.028)\end{array}$ & $\begin{array}{l}-0.0003 \\
(0.028)\end{array}$ & $\begin{array}{l}0.038^{*} \\
(0.021)\end{array}$ & $\begin{array}{l}0.046^{*} \\
(0.025)\end{array}$ \\
\hline Minimum Wage & $\begin{array}{c}0.133 \\
(0.189)\end{array}$ & $\begin{array}{c}0.133 \\
(0.189)\end{array}$ & $\begin{array}{c}0.140 \\
(0.166)\end{array}$ & $\begin{array}{c}0.088 \\
(0.194)\end{array}$ & $\begin{array}{c}0.280 \\
(0.238)\end{array}$ & $\begin{array}{c}0.281 \\
(0.238)\end{array}$ & $\begin{array}{c}0.127 \\
(0.175)\end{array}$ & $\begin{array}{c}0.051 \\
(0.199)\end{array}$ \\
\hline Welfare Waiver Stick & $\begin{array}{l}-0.171 \\
(0.259)\end{array}$ & $\begin{array}{l}-0.171 \\
(0.259)\end{array}$ & $\begin{array}{l}-0.217 \\
(0.235)\end{array}$ & $\begin{array}{c}0.072 \\
(0.225)\end{array}$ & $\begin{array}{l}-0.397 \\
(0.344)\end{array}$ & $\begin{array}{l}-0.398 \\
(0.344)\end{array}$ & $\begin{array}{l}-0.119 \\
(0.246)\end{array}$ & $\begin{array}{l}-0.091 \\
(0.278)\end{array}$ \\
\hline Welfare Waiver Carrot & $\begin{array}{c}0.043 \\
(0.190)\end{array}$ & $\begin{array}{c}0.044 \\
(0.190)\end{array}$ & $\begin{array}{c}0.085 \\
(0.166)\end{array}$ & $\begin{array}{c}0.106 \\
(0.176)\end{array}$ & $\begin{array}{l}-0.014 \\
(0.218)\end{array}$ & $\begin{array}{l}-0.014 \\
(0.218)\end{array}$ & $\begin{array}{l}-0.104 \\
(0.170)\end{array}$ & $\begin{array}{l}-0.255 \\
(0.199)\end{array}$ \\
\hline African American & $\begin{array}{c}-0.171^{* *} \\
(0.085)\end{array}$ & $\begin{array}{c}-0.175^{* *} \\
(0.087)\end{array}$ & $\begin{array}{l}-0.117 \\
(0.077)\end{array}$ & $\begin{array}{l}-0.129 \\
(0.086)\end{array}$ & $\begin{array}{c}0.088 \\
(0.100)\end{array}$ & $\begin{array}{c}0.085 \\
(0.103)\end{array}$ & $\begin{array}{c}0.346^{* *} \\
(0.076)\end{array}$ & $\begin{array}{c}0.388^{* *} \\
(0.086)\end{array}$ \\
\hline Hispanic & $\begin{array}{c}-0.184 * * \\
(0.096)\end{array}$ & $\begin{array}{l}-0.188^{*} \\
(0.098)\end{array}$ & $\begin{array}{l}-0.140^{*} \\
(0.085)\end{array}$ & $\begin{array}{l}-0.101 \\
(0.095)\end{array}$ & $\begin{array}{l}0.209^{*} \\
(0.111)\end{array}$ & $\begin{array}{l}0.207^{*} \\
(0.114)\end{array}$ & $\begin{array}{l}0.199 * * \\
(0.090)\end{array}$ & $\begin{array}{l}0.133^{* *} \\
(0.105)\end{array}$ \\
\hline 12 Years of Schooling & $\begin{array}{c}0.365^{* *} \\
(0.070)\end{array}$ & $\begin{array}{c}0.365^{* *} \\
(0.070)\end{array}$ & $\begin{array}{l}0.420^{* *} \\
(0.064)\end{array}$ & $\begin{array}{l}0.509^{* *} \\
(0.072)\end{array}$ & $\begin{array}{c}-0.549 * * \\
(0.084)\end{array}$ & $\begin{array}{c}-0.549 * * \\
(0.084)\end{array}$ & $\begin{array}{c}-0.600 * * \\
(0.066)\end{array}$ & $\begin{array}{c}-0.670^{* *} \\
(0.077)\end{array}$ \\
\hline Age & $\begin{array}{c}-0.049 * * \\
(0.007)\end{array}$ & $\begin{array}{c}-0.049 * * \\
(0.007)\end{array}$ & $\begin{array}{c}-0.040 * * \\
(0.006)\end{array}$ & $\begin{array}{c}-0.026 * * \\
(0.006)\end{array}$ & $\begin{array}{c}-0.039 * * \\
(0.007)\end{array}$ & $\begin{array}{c}-0.039 * * \\
(0.007)\end{array}$ & $\begin{array}{c}-0.029 * * \\
(0.005)\end{array}$ & $\begin{array}{c}-0.026^{* *} \\
(0.006)\end{array}$ \\
\hline Never Married & $\begin{array}{c}-0.441^{* *} \\
(0.084)\end{array}$ & $\begin{array}{c}-0.441^{* *} \\
(0.084)\end{array}$ & $\begin{array}{c}-0.367^{* *} \\
(0.076)\end{array}$ & $\begin{array}{c}-0.276^{* *} \\
(0.085)\end{array}$ & $\begin{array}{c}0.203^{* *} \\
(0.097)\end{array}$ & $\begin{array}{c}0.204^{* *} \\
(0.097)\end{array}$ & $\begin{array}{c}0.229^{* *} \\
(0.076)\end{array}$ & $\begin{array}{c}0.279 * * \\
(0.088)\end{array}$ \\
\hline \# of Children $<18$ & $\begin{array}{c}0.010 \\
(0.039)\end{array}$ & $\begin{array}{c}0.011 \\
(0.039)\end{array}$ & $\begin{array}{l}-0.005 \\
(0.035)\end{array}$ & $\begin{array}{c}0.038 \\
(0.038)\end{array}$ & $\begin{array}{c}0.079 \\
(0.052)\end{array}$ & $\begin{array}{c}0.079 \\
(0.052)\end{array}$ & $\begin{array}{c}0.035 \\
(0.040)\end{array}$ & $\begin{array}{c}0.017 \\
(0.045)\end{array}$ \\
\hline Age of Youngest Child & $\begin{array}{c}0.003 \\
(0.013)\end{array}$ & $\begin{array}{c}0.003 \\
(0.013)\end{array}$ & $\begin{array}{c}0.008 \\
(0.011)\end{array}$ & $\begin{array}{c}-0.012 \\
(0.013)\end{array}$ & $\begin{array}{l}-0.016 \\
(0.014)\end{array}$ & $\begin{array}{l}-0.016 \\
(0.014)\end{array}$ & $\begin{array}{l}-0.016 \\
(0.011)\end{array}$ & $\begin{array}{l}-0.024^{*} \\
(0.012)\end{array}$ \\
\hline \# of Children < 6 & $\begin{array}{c}-0.284^{* *} \\
(0.063)\end{array}$ & $\begin{array}{c}-0.284^{* *} \\
(0.063)\end{array}$ & $\begin{array}{c}-0.292 * * \\
(0.057)\end{array}$ & $\begin{array}{c}-0.363 * * \\
(0.068)\end{array}$ & $\begin{array}{c}0.160^{* *} \\
(0.079)\end{array}$ & $\begin{array}{c}0.160^{* *} \\
(0.079)\end{array}$ & $\begin{array}{c}0.137^{* *} \\
(0.062)\end{array}$ & $\begin{array}{c}0.103 \\
(0.074)\end{array}$ \\
\hline Disability & $\begin{array}{c}-0.466 * * \\
(0.092)\end{array}$ & $\begin{array}{c}-0.466 * * \\
(0.092)\end{array}$ & $\begin{array}{c}-0.596 * * \\
(0.085)\end{array}$ & $\begin{array}{c}-0.615^{* *} \\
(0.092)\end{array}$ & $\begin{array}{c}0.815^{* *} \\
(0.103)\end{array}$ & $\begin{array}{c}0.817^{* *} \\
(0.103)\end{array}$ & $\begin{array}{c}0.769 * * \\
(0.083)\end{array}$ & $\begin{array}{c}0.844 * * \\
(0.094)\end{array}$ \\
\hline Disability Variable Missing & $\begin{array}{l}-0.106 \\
(0.118) \\
\end{array}$ & $\begin{array}{r}-0.106 \\
(0.118) \\
\end{array}$ & $\begin{array}{c}-0.209 * * \\
(0.106) \\
\end{array}$ & $\begin{array}{c}-0.428 * * \\
(0.127) \\
\end{array}$ & $\begin{array}{c}0.363^{* *} \\
(0.139) \\
\end{array}$ & $\begin{array}{c}0.363^{* *} \\
(0.139) \\
\end{array}$ & $\begin{array}{c}0.332^{* *} \\
(0.107) \\
\end{array}$ & $\begin{array}{c}0.009 \\
(0.140) \\
\end{array}$ \\
\hline
\end{tabular}


Table 2A. (continued) Duration Models of Employment and Non-employment Spells Single Mothers with a Maximum of Twelve Years of Education - Left-censored Spells

\begin{tabular}{|c|c|c|c|c|c|c|c|c|}
\hline & \multicolumn{4}{|c|}{ Left-censored non-employment spells } & \multicolumn{4}{|c|}{ Left-censored employment spells } \\
\hline & $\begin{array}{c}\text { Constant } \\
\text { Probabilities }\end{array}$ & $\begin{array}{c}\text { Variable } \\
\text { Probabilities }\end{array}$ & $\begin{array}{c}\text { Last Month } \\
\text { Dummy }\end{array}$ & $\begin{array}{c}\text { Last Month } \\
\text { Data }\end{array}$ & $\begin{array}{c}\text { Constant } \\
\text { Probabilities }\end{array}$ & $\begin{array}{c}\text { Variable } \\
\text { Probabilities }\end{array}$ & $\begin{array}{c}\text { Last Month } \\
\text { Dummy }\end{array}$ & $\begin{array}{c}\text { Last Month } \\
\text { Data }\end{array}$ \\
\hline log(duration) & $\begin{array}{c}-0.363^{* *} \\
(0.041)\end{array}$ & $\begin{array}{c}-0.363^{* *} \\
(0.041)\end{array}$ & $\begin{array}{l}0.288^{* *} \\
(0.124)\end{array}$ & $\begin{array}{c}-0.705^{* *} \\
(0.064)\end{array}$ & $\begin{array}{c}-0.314^{* *} \\
(0.049)\end{array}$ & $\begin{array}{c}-0.314^{* *} \\
(0.049)\end{array}$ & $\begin{array}{l}0.432^{* *} \\
(0.150)\end{array}$ & $\begin{array}{c}-0.707^{* *} \\
(0.065)\end{array}$ \\
\hline Square of $\log$ (duration) & & & $\begin{array}{c}-0.188 * * \\
(0.035)\end{array}$ & & & & $\begin{array}{c}-0.238 * * \\
(0.040)\end{array}$ & \\
\hline Last-Month Dummy & - & - & $\begin{array}{c}0.700 * * \\
(0.064)\end{array}$ & - & - & - & $\begin{array}{l}1.359 * * \\
(0.065)\end{array}$ & - \\
\hline \multicolumn{9}{|l|}{ Unobserved Heterogeneity } \\
\hline Theta1 & $\begin{array}{l}-1.195^{*} \\
(0.708)\end{array}$ & $\begin{array}{l}-1.193^{*} \\
(0.708)\end{array}$ & $\begin{array}{l}-1.121^{*} \\
(0.673)\end{array}$ & $\begin{array}{l}1.386^{*} \\
(0.846)\end{array}$ & $\begin{array}{c}-2.971^{* *} \\
(0.854)\end{array}$ & $\begin{array}{c}-2.970^{* *} \\
(0.854)\end{array}$ & $\begin{array}{c}-3.579 * * \\
(0.660)\end{array}$ & $\begin{array}{l}-0.369 \\
(0.800)\end{array}$ \\
\hline Theta2 & $\begin{array}{l}-1.131 \\
(0.707)\end{array}$ & $\begin{array}{l}-1.132 \\
(0.707)\end{array}$ & $\begin{array}{c}-1.993 * * \\
(0.632)\end{array}$ & $\begin{array}{c}0.685 \\
(0.718)\end{array}$ & $\begin{array}{c}-3.691 * * \\
(0.842)\end{array}$ & $\begin{array}{c}-3.692 * * \\
(0.843)\end{array}$ & $\begin{array}{c}-4.048 * * \\
(0.657)\end{array}$ & $\begin{array}{l}-0.878 \\
(0.742)\end{array}$ \\
\hline Heterogeneity Probability & $\begin{array}{c}0.396^{* *} \\
(0.022)\end{array}$ & $\begin{array}{l}0.396 * * \\
(0.022)\end{array}$ & $\begin{array}{l}0.365^{* *} \\
(0.106)\end{array}$ & $\begin{array}{l}0.265^{* *} \\
(0.125)\end{array}$ & & & & \\
\hline
\end{tabular}

1. We allow unobserved heterogeneity to be correlated across different type of spells (see Section 4.4). For each model, the heterogeneity probability is the same for each of the four types of spells.

2. Year dummies are included in each regression and their coefficients are omitted.

3. Standard errors are in parentheses.

4. The maximum welfare benefit variable has been divided by 10,000 .

* Significant at the $10 \%$ level. ** Significant at the $5 \%$ level. 
Table 2B. Duration Models of Employment and Non-employment Spells Single Mothers with a Maximum of Twelve Years of Education - Fresh Spells

\begin{tabular}{|c|c|c|c|c|c|c|c|c|}
\hline & \multicolumn{4}{|c|}{ Fresh non-employment spells } & \multicolumn{4}{|c|}{ Fresh employment spells } \\
\hline & $\begin{array}{c}\text { Constant } \\
\text { Probabilities }\end{array}$ & $\begin{array}{c}\text { Variable } \\
\text { Probabilities }\end{array}$ & $\begin{array}{c}\text { Last Month } \\
\text { Dummy }\end{array}$ & $\begin{array}{c}\text { Last Month } \\
\text { Data }\end{array}$ & $\begin{array}{c}\text { Constant } \\
\text { Probabilities }\end{array}$ & $\begin{array}{c}\text { Variable } \\
\text { Probabilities }\end{array}$ & $\begin{array}{l}\text { Last Month } \\
\text { Dummy }\end{array}$ & $\begin{array}{c}\text { Last Month } \\
\text { Data }\end{array}$ \\
\hline Maximum Welfare Benefit & $\begin{array}{l}-3.414 \\
(2.252)\end{array}$ & $\begin{array}{l}-3.419 \\
(2.252)\end{array}$ & $\begin{array}{c}-7.348^{* *} \\
(2.462)\end{array}$ & $\begin{array}{l}-3.875 \\
(3.666)\end{array}$ & $\begin{array}{l}8.481^{* *} \\
(2.338)\end{array}$ & $\begin{array}{l}8.474^{* *} \\
(2.339)\end{array}$ & $\begin{array}{l}5.542^{* *} \\
(2.393)\end{array}$ & $\begin{array}{c}11.675^{* *} \\
(3.924)\end{array}$ \\
\hline Unemployment Rate & $\begin{array}{c}-0.054^{* *} \\
(0.021)\end{array}$ & $\begin{array}{c}-0.054^{* *} \\
(0.021)\end{array}$ & $\begin{array}{c}-0.054 * * \\
(0.023)\end{array}$ & $\begin{array}{l}-0.033 \\
(0.036)\end{array}$ & $\begin{array}{l}0.060^{* *} \\
(0.021)\end{array}$ & $\begin{array}{l}0.060^{* *} \\
(0.021)\end{array}$ & $\begin{array}{c}0.023 \\
(0.022)\end{array}$ & $\begin{array}{c}0.055 \\
(0.039)\end{array}$ \\
\hline Minimum Wage & $\begin{array}{l}-0.150 \\
(0.181)\end{array}$ & $\begin{array}{l}-0.149 \\
(0.182)\end{array}$ & $\begin{array}{c}0.072 \\
(0.189)\end{array}$ & $\begin{array}{l}-0.232 \\
(0.296)\end{array}$ & $\begin{array}{c}-0.504 * * \\
(0.198)\end{array}$ & $\begin{array}{c}-0.505^{* *} \\
(0.198)\end{array}$ & $\begin{array}{l}-0.094 \\
(0.200)\end{array}$ & $\begin{array}{c}0.418 \\
(0.321)\end{array}$ \\
\hline Welfare Waiver Stick & $\begin{array}{l}-0.321 \\
(0.199)\end{array}$ & $\begin{array}{l}-0.322 \\
(0.199)\end{array}$ & $\begin{array}{l}-0.309 \\
(0.208)\end{array}$ & $\begin{array}{l}-0.215 \\
(0.309)\end{array}$ & $\begin{array}{c}0.176 \\
(0.181)\end{array}$ & $\begin{array}{c}0.176 \\
(0.182)\end{array}$ & $\begin{array}{l}-0.149 \\
(0.204)\end{array}$ & $\begin{array}{l}-0.508 \\
(0.348)\end{array}$ \\
\hline Welfare Waiver Carrot & $\begin{array}{l}0.380^{* *} \\
(0.127)\end{array}$ & $\begin{array}{l}0.380^{* *} \\
(0.128)\end{array}$ & $\begin{array}{l}0.370^{* *} \\
(0.150)\end{array}$ & $\begin{array}{c}0.243 \\
(0.223)\end{array}$ & $\begin{array}{l}-0.120 \\
(0.139)\end{array}$ & $\begin{array}{l}-0.120 \\
(0.139)\end{array}$ & $\begin{array}{l}-0.060 \\
(0.148)\end{array}$ & $\begin{array}{l}-0.276 \\
(0.235)\end{array}$ \\
\hline African American & $\begin{array}{c}-0.200^{* *} \\
(0.076)\end{array}$ & $\begin{array}{c}-0.196^{* *} \\
(0.077)\end{array}$ & $\begin{array}{c}-0.332 * * \\
(0.087)\end{array}$ & $\begin{array}{l}-0.089 \\
(0.128)\end{array}$ & $\begin{array}{c}0.061 \\
(0.079)\end{array}$ & $\begin{array}{c}0.061 \\
(0.080)\end{array}$ & $\begin{array}{c}0.065 \\
(0.083)\end{array}$ & $\begin{array}{l}0.247^{*} \\
(0.144)\end{array}$ \\
\hline Hispanic & $\begin{array}{l}-0.049 \\
(0.086)\end{array}$ & $\begin{array}{l}-0.046 \\
(0.086)\end{array}$ & $\begin{array}{c}0.023 \\
(0.097)\end{array}$ & $\begin{array}{c}0.194 \\
(0.149)\end{array}$ & $\begin{array}{l}-0.012 \\
(0.097)\end{array}$ & $\begin{array}{l}-0.012 \\
(0.098)\end{array}$ & $\begin{array}{l}-0.062 \\
(0.099)\end{array}$ & $\begin{array}{l}-0.093 \\
(0.164)\end{array}$ \\
\hline 12 Years of Schooling & $\begin{array}{l}0.211^{* *} \\
(0.063)\end{array}$ & $\begin{array}{l}0.211^{* *} \\
(0.063)\end{array}$ & $\begin{array}{l}0.226^{* *} \\
(0.070)\end{array}$ & $\begin{array}{l}0.284^{* *} \\
(0.111)\end{array}$ & $\begin{array}{c}-0.420 * * \\
(0.069)\end{array}$ & $\begin{array}{c}-0.420 * * \\
(0.069)\end{array}$ & $\begin{array}{c}-0.358^{* *} \\
(0.071)\end{array}$ & $\begin{array}{c}-0.365^{* *} \\
(0.119)\end{array}$ \\
\hline Age & $\begin{array}{c}0.001 \\
(0.006)\end{array}$ & $\begin{array}{c}0.001 \\
(0.006)\end{array}$ & $\begin{array}{c}0.002 \\
(0.006)\end{array}$ & $\begin{array}{l}-0.001 \\
(0.009)\end{array}$ & $\begin{array}{c}-0.015 * * \\
(0.006)\end{array}$ & $\begin{array}{c}-0.015^{* *} \\
(0.006)\end{array}$ & $\begin{array}{c}-0.032 * * \\
(0.007)\end{array}$ & $\begin{array}{c}-0.039 * * \\
(0.011)\end{array}$ \\
\hline Never Married & $\begin{array}{l}-0.075 \\
(0.075)\end{array}$ & $\begin{array}{l}-0.074 \\
(0.075)\end{array}$ & $\begin{array}{c}-0.131 \\
(0.084)\end{array}$ & $\begin{array}{l}-0.130 \\
(0.130)\end{array}$ & $\begin{array}{c}0.079 \\
(0.080)\end{array}$ & $\begin{array}{c}0.079 \\
(0.080)\end{array}$ & $\begin{array}{c}0.080 \\
(0.083)\end{array}$ & $\begin{array}{c}0.239 * \\
(0.146)\end{array}$ \\
\hline \# of Children < 18 & $\begin{array}{c}-0.063^{*} \\
(0.038)\end{array}$ & $\begin{array}{c}-0.063^{*} \\
(0.038)\end{array}$ & $\begin{array}{c}0.021 \\
(0.041)\end{array}$ & $\begin{array}{l}-0.004 \\
(0.061)\end{array}$ & $\begin{array}{l}-0.018 \\
(0.037)\end{array}$ & $\begin{array}{l}-0.018 \\
(0.037)\end{array}$ & $\begin{array}{l}-0.005 \\
(0.039)\end{array}$ & $\begin{array}{c}0.061 \\
(0.064)\end{array}$ \\
\hline Age of Youngest Child & $\begin{array}{c}0.004 \\
(0.011)\end{array}$ & $\begin{array}{c}0.003 \\
(0.011)\end{array}$ & $\begin{array}{c}0.005 \\
(0.013)\end{array}$ & $\begin{array}{l}-0.001 \\
(0.019)\end{array}$ & $\begin{array}{l}-0.006 \\
(0.012)\end{array}$ & $\begin{array}{l}-0.006 \\
(0.012)\end{array}$ & $\begin{array}{l}-0.002 \\
(0.012)\end{array}$ & $\begin{array}{c}0.002 \\
(0.020)\end{array}$ \\
\hline \# of Children < 6 & $\begin{array}{c}-0.128^{* *} \\
(0.064)\end{array}$ & $\begin{array}{c}-0.128^{*} \\
(0.064)\end{array}$ & $\begin{array}{c}-0.157^{* *} \\
(0.071)\end{array}$ & $\begin{array}{c}-0.232 * * \\
(0.111)\end{array}$ & $\begin{array}{l}-0.023 \\
(0.062)\end{array}$ & $\begin{array}{l}-0.023 \\
(0.062)\end{array}$ & $\begin{array}{c}0.003 \\
(0.065)\end{array}$ & $\begin{array}{c}-0.060 \\
(0.110)\end{array}$ \\
\hline Disability & $\begin{array}{c}-0.595 * * \\
(0.083)\end{array}$ & $\begin{array}{c}-0.596 * * \\
(0.083)\end{array}$ & $\begin{array}{c}-0.486 * * \\
(0.092)\end{array}$ & $\begin{array}{c}-0.590 * * \\
(0.148)\end{array}$ & $\begin{array}{c}0.586^{* *} \\
(0.090)\end{array}$ & $\begin{array}{c}0.587^{* *} \\
(0.090)\end{array}$ & $\begin{array}{c}0.480^{* *} \\
(0.090)\end{array}$ & $\begin{array}{c}0.426^{* *} \\
(0.158)\end{array}$ \\
\hline Disability Variable Missing & $\begin{array}{c}-0.283^{*} \\
(0.157) \\
\end{array}$ & $\begin{array}{c}-0.283^{*} \\
(0.157) \\
\end{array}$ & $\begin{array}{c}-0.443^{* *} \\
(0.149) \\
\end{array}$ & $\begin{array}{c}-0.715 * * \\
(0.278) \\
\end{array}$ & $\begin{array}{c}0.702 * * \\
(0.155) \\
\end{array}$ & $\begin{array}{c}0.702^{* *} \\
(0.155) \\
\end{array}$ & $\begin{array}{c}0.152 \\
(0.143) \\
\end{array}$ & $\begin{array}{c}-0.418 \\
(0.270) \\
\end{array}$ \\
\hline
\end{tabular}


Table 2B (continued) Duration Models of Employment and Non-employment Spells Single Mothers with a Maximum of Twelve Years of Education - Fresh Spells

\begin{tabular}{|c|c|c|c|c|c|c|c|c|}
\hline & \multicolumn{4}{|c|}{ Fresh non-employment spells } & \multicolumn{4}{|c|}{ Fresh employment spells } \\
\hline & $\begin{array}{c}\text { Constant } \\
\text { Probabilities }\end{array}$ & $\begin{array}{c}\text { Variable } \\
\text { Probabilities }\end{array}$ & $\begin{array}{l}\text { Last Month } \\
\text { Dummy }\end{array}$ & $\begin{array}{c}\text { Last Month } \\
\text { Data }\end{array}$ & $\begin{array}{c}\text { Constant } \\
\text { Probabilities }\end{array}$ & $\begin{array}{c}\text { Variable } \\
\text { Probabilities }\end{array}$ & $\begin{array}{l}\text { Last Month } \\
\text { Dummy }\end{array}$ & $\begin{array}{c}\text { Last Month } \\
\text { Data }\end{array}$ \\
\hline $\log ($ duration) & $\begin{array}{c}0.103 \\
(0.099)\end{array}$ & $\begin{array}{c}0.101 \\
(0.099)\end{array}$ & $\begin{array}{l}-0.041 \\
(0.100)\end{array}$ & $\begin{array}{c}-0.688^{* *} \\
(0.116)\end{array}$ & $\begin{array}{c}0.089 \\
(0.101)\end{array}$ & $\begin{array}{c}0.087 \\
(0.101)\end{array}$ & $\begin{array}{l}0.362^{* *} \\
(0.109)\end{array}$ & $\begin{array}{c}-0.706^{* *} \\
(0.135)\end{array}$ \\
\hline Square of $\log$ (duration) & $\begin{array}{l}-0.019 \\
(0.031)\end{array}$ & $\begin{array}{l}-0.019 \\
(0.031)\end{array}$ & $\begin{array}{c}-0.116^{* *} \\
(0.037)\end{array}$ & & $\begin{array}{l}0.065^{*} \\
(0.035)\end{array}$ & $\begin{array}{l}0.065^{*} \\
(0.035)\end{array}$ & $\begin{array}{c}-0.278^{* *} \\
(0.040)\end{array}$ & \\
\hline Last-Month Dummy & - & - & $\begin{array}{l}0.950 * * \\
(0.060)\end{array}$ & - & - & - & $\begin{array}{l}1.360^{* *} \\
(0.061)\end{array}$ & - \\
\hline \multicolumn{9}{|l|}{ Unobserved Heterogeneity } \\
\hline Theta1 & $\begin{array}{c}0.541 \\
(0.662)\end{array}$ & $\begin{array}{c}0.533 \\
(0.662)\end{array}$ & $\begin{array}{c}-2.448^{* *} \\
(0.694)\end{array}$ & $\begin{array}{l}-0.004 \\
(1.117)\end{array}$ & $\begin{array}{c}-2.118^{* *} \\
(0.711)\end{array}$ & $\begin{array}{c}-2.113^{* *} \\
(0.713)\end{array}$ & $\begin{array}{l}-1.169 \\
(0.743)\end{array}$ & $\begin{array}{l}-0.319 \\
(1.224)\end{array}$ \\
\hline Theta2 & $\begin{array}{c}-1.634 * * \\
(0.663)\end{array}$ & $\begin{array}{c}-1.640 * * \\
(0.663)\end{array}$ & $\begin{array}{l}-1.251^{*} \\
(0.694)\end{array}$ & $\begin{array}{c}1.454 \\
(1.104)\end{array}$ & $\begin{array}{c}0.264 \\
(0.711)\end{array}$ & $\begin{array}{c}0.270 \\
(0.713)\end{array}$ & $\begin{array}{l}-2.254 \\
(0.740)\end{array}$ & $\begin{array}{l}-2.172^{*} \\
(1.247)\end{array}$ \\
\hline Heterogeneity Probability & $\begin{array}{l}0.396^{* *} \\
(0.022)\end{array}$ & $\begin{array}{l}0.396 * * \\
(0.022)\end{array}$ & $\begin{array}{l}0.365 * * \\
(0.106)\end{array}$ & $\begin{array}{l}0.265^{* *} \\
(0.125)\end{array}$ & & & & \\
\hline
\end{tabular}

Notes: See notes to Table 2A. 
Table 2C. Misreporting Probabilities Due to Seam Bias Constant Probabilities vs. Probabilities Varying by Race

\begin{tabular}{lcc|cc}
\hline \hline & \multicolumn{3}{c}{ Panel A: Parameter Estimates } \\
\hline & \multicolumn{2}{c}{ Non-employment Spells } & \multicolumn{2}{c}{ Employment Spells } \\
\cline { 2 - 5 } & Constant & Probabilities Varying & Constant & Probabilities Varying \\
& Probabilities & with Race & $0.989^{* *}$ & with Race \\
\hline Month 1 Intercept & $0.275^{*}$ & $0.796^{* *}$ & $(0.149)$ & 0.0986 \\
& $(0.142)$ & $(0.168)$ & $0.410^{* *}$ & $(0.17)$ \\
Month 2 Intercept & -0.174 & 0.211 & $(0.158)$ & $-0.350^{*}$ \\
& $(0.174)$ & $(0.181)$ & $0.345^{* *}$ & $(0.198)$ \\
Month 3 Intercept & -0.236 & 0.1349 & $(0.161)$ & $-0.375^{*}$ \\
& $(0.177)$ & $(0.184)$ & & $(0.194)$ \\
Minority Dummy & & $0.384^{* *}$ & & $0.299^{*}$ \\
& & $(0.159)$ & $(0.156)$ \\
\hline
\end{tabular}

Panel B: Misreporting Probabilities

\begin{tabular}{|c|c|c|c|c|c|c|}
\hline & \multicolumn{3}{|c|}{ Non-employment Spells } & \multicolumn{3}{|c|}{ Employment Spells } \\
\hline & $\begin{array}{c}\text { Constant } \\
\text { Probabilities }\end{array}$ & $\begin{array}{r}\text { Probabili } \\
\text { wit }\end{array}$ & $\begin{array}{l}\text { es Varying } \\
\text { Race }\end{array}$ & $\begin{array}{c}\text { Constant } \\
\text { Probabilities }\end{array}$ & $\begin{array}{r}\text { Probabili } \\
\text { wit }\end{array}$ & $\begin{array}{l}\text { es Varying } \\
\text { Race }\end{array}$ \\
\hline Month 1 & $\begin{array}{c}0.568 * * \\
(0.035)\end{array}$ & $\begin{array}{c}\text { White } \\
\text { Minorities }\end{array}$ & $\begin{array}{l}0.525^{* *} \\
(0.042) \\
0.598^{* *} \\
(0.039)\end{array}$ & $\begin{array}{c}0.729 * * \\
(0.029)\end{array}$ & $\begin{array}{c}\text { White } \\
\text { Minorities }\end{array}$ & $\begin{array}{l}0.689 * * \\
(0.036) \\
0.765 * * \\
(0.030)\end{array}$ \\
\hline Month 2 & $\begin{array}{c}0.456 * * \\
(0.043)\end{array}$ & $\begin{array}{c}\text { White } \\
\text { Minorities }\end{array}$ & $\begin{array}{l}0.413^{* *} \\
(0.048) \\
0.487^{* *} \\
(0.040)\end{array}$ & $\begin{array}{l}0.601 * * \\
(0.038)\end{array}$ & $\begin{array}{c}\text { White } \\
\text { Minorities }\end{array}$ & $\begin{array}{l}0.553^{* *} \\
(0.045) \\
0.645 * * \\
(0.035)\end{array}$ \\
\hline Month 3 & $\begin{array}{c}0.441 * * \\
(0.044)\end{array}$ & $\begin{array}{c}\text { White } \\
\text { Minorities }\end{array}$ & $\begin{array}{l}0.407 * * \\
(0.047) \\
0.481^{* *} \\
(0.037) \\
\end{array}$ & $\begin{array}{c}0.585 * * \\
(0.039)\end{array}$ & $\begin{array}{c}\text { White } \\
\text { Minorities }\end{array}$ & $\begin{array}{l}0.534 * * \\
(0.046) \\
0.627^{* *} \\
(0.035)\end{array}$ \\
\hline
\end{tabular}

Notes: See notes to Table 2A. Also:

1. For the constant probability model, the parameters in Panel A are based on the reparameterization specified in Section 5.1.

2. For the model with seam bias probabilities varying with the minority dummy variable, the parameters in Panel A are specified in equation (4.11).

3. Standard errors in Panel B are calculated using the delta method. 
Table 3A. Expected Durations and the Effects of Changes in Macro and Public Policy Variables Employment and Non-employment Spells

\begin{tabular}{|c|c|c|c|c|c|c|c|c|}
\hline \multicolumn{9}{|l|}{ Changes with respect to: } \\
\hline $\begin{array}{l}\text { Carrot waiver } \\
\text { (implemented - not implemented) }\end{array}$ & $\begin{array}{l}-0.639 \\
(2.892)\end{array}$ & $\begin{array}{l}-0.654 \\
(2.827)\end{array}$ & $\begin{array}{l}-1.313 \\
(2.608)\end{array}$ & $\begin{array}{l}-1.498 \\
(2.497)\end{array}$ & $\begin{array}{c}0.168 \\
(2.655)\end{array}$ & $\begin{array}{c}0.165 \\
(2.537)\end{array}$ & $\begin{array}{l}1.436 \\
(2.253)\end{array}$ & $\begin{array}{c}3.055 \\
(2.225)\end{array}$ \\
\hline $\begin{array}{l}\text { Stick waiver } \\
\text { (implemented - not implemented) }\end{array}$ & $\begin{array}{c}2.427 \\
(3.458)\end{array}$ & $\begin{array}{c}2.427 \\
(3.503)\end{array}$ & $\begin{array}{c}3.228 \\
(3.416)\end{array}$ & $\begin{array}{l}-1.005 \\
(3.195)\end{array}$ & $\begin{array}{c}4.483 \\
(3.514)\end{array}$ & $\begin{array}{c}4.485 \\
(3.537)\end{array}$ & $\begin{array}{c}1.639 \\
(3.400)\end{array}$ & $\begin{array}{c}1.125 \\
(3.374)\end{array}$ \\
\hline Minimum wage increasing by $10 \%$ & $\begin{array}{l}-0.768 \\
(1.423)\end{array}$ & $\begin{array}{l}-0.773 \\
(1.079)\end{array}$ & $\begin{array}{l}-0.841 \\
(1.142)\end{array}$ & $\begin{array}{l}-0.485 \\
(1.345)\end{array}$ & $\begin{array}{l}-1.381 \\
(1.043)\end{array}$ & $\begin{array}{l}-1.383 \\
(1.201)\end{array}$ & $\begin{array}{l}-0.707 \\
(0.972)\end{array}$ & $\begin{array}{l}-0.250 \\
(0.873)\end{array}$ \\
\hline $\begin{array}{l}\text { Unemployment rate } \\
\text { increasing by } 25 \%\end{array}$ & \multicolumn{4}{|c|}{ Fresh non-employment spells } & \multicolumn{4}{|c|}{ Fresh employment spells } \\
\hline $\begin{array}{l}\text { Average Expected Duration (in } \\
\text { months) }\end{array}$ & $\begin{array}{c}11.821^{* *} \\
(0.516)\end{array}$ & $\begin{array}{c}11.827 * * \\
(0.514)\end{array}$ & $\begin{array}{c}16.458 * * \\
(1.312)\end{array}$ & $\begin{array}{c}23.342 * * \\
(2.254)\end{array}$ & $\begin{array}{c}11.929 * * \\
(0.495)\end{array}$ & $\begin{array}{c}11.920 * * \\
(0.497)\end{array}$ & $\begin{array}{c}27.711 * * \\
(1.394)\end{array}$ & $\begin{array}{c}32.563^{* *} \\
(2.197)\end{array}$ \\
\hline \multicolumn{9}{|l|}{ Changes with respect to: } \\
\hline $\begin{array}{l}\text { Maximum welfare benefits } \\
\text { increasing by } 10 \%\end{array}$ & $\begin{array}{l}0.118 \\
(0.119)\end{array}$ & $\begin{array}{c}0.119 \\
(0.149)\end{array}$ & $\begin{array}{c}0.375^{* *} \\
(0.136)\end{array}$ & $\begin{array}{l}0.196 \\
(0.407)\end{array}$ & $\begin{array}{c}-0.220^{* *} \\
(0.070)\end{array}$ & $\begin{array}{c}-0.220 * * \\
(0.062)\end{array}$ & $\begin{array}{c}-0.341^{*} \\
(0.206)\end{array}$ & $\begin{array}{l}-0.565 \\
(0.446)\end{array}$ \\
\hline $\begin{array}{l}\text { Carrot waiver } \\
\text { (implemented - not implemented) }\end{array}$ & $\begin{array}{c}-3.099 * * \\
(1.009)\end{array}$ & $\begin{array}{c}-3.103^{* *} \\
(0.933)\end{array}$ & $\begin{array}{l}-4.531^{* *} \\
(1.703)\end{array}$ & $\begin{array}{l}-3.139 \\
(2.790)\end{array}$ & $\begin{array}{c}0.881 \\
(1.074)\end{array}$ & $\begin{array}{c}0.885 \\
(1.014)\end{array}$ & $\begin{array}{c}0.988 \\
(2.471)\end{array}$ & $\begin{array}{c}3.471 \\
(2.826)\end{array}$ \\
\hline $\begin{array}{l}\text { Stick waiver } \\
\text { (implemented - not implemented) }\end{array}$ & $\begin{array}{c}3.138 \\
(2.100)\end{array}$ & $\begin{array}{c}3.152 \\
(2.075)\end{array}$ & $\begin{array}{c}4.388 \\
(3.212)\end{array}$ & $\begin{array}{c}2.950 \\
(4.323)\end{array}$ & $\begin{array}{l}-1.222 \\
(1.217)\end{array}$ & $\begin{array}{l}-1.220 \\
(1.228)\end{array}$ & $\begin{array}{c}2.453 \\
(3.355)\end{array}$ & $\begin{array}{c}6.266 \\
(4.187)\end{array}$ \\
\hline Minimum wage increasing by $10 \%$ & $\begin{array}{c}0.545 \\
(0.613)\end{array}$ & $\begin{array}{c}0.540 \\
(0.715)\end{array}$ & $\begin{array}{l}-0.375 \\
(1.027)\end{array}$ & $\begin{array}{c}1.238 \\
(1.420)\end{array}$ & $\begin{array}{l}1.484^{* *} \\
(0.538)\end{array}$ & $\begin{array}{l}1.486 * * \\
(0.570)\end{array}$ & $\begin{array}{c}0.608 \\
(1.180)\end{array}$ & $\begin{array}{l}-2.133 \\
(1.499)\end{array}$ \\
\hline
\end{tabular}

Note: See notes to Table 2A. Standard errors are calculated using the delta method. 
Table 3B. The Effects of Changes in Demographic Variables - Employment and Non-employment Spells

\begin{tabular}{|c|c|c|c|c|c|c|c|c|}
\hline & \multicolumn{4}{|c|}{ Left-censored non-employment spells } & \multicolumn{4}{|c|}{ Left-censored employment spells } \\
\hline & $\begin{array}{c}\text { Constant } \\
\text { Misreporting } \\
\text { Probabilities } \\
\end{array}$ & $\begin{array}{c}\text { Variable } \\
\text { Misreporting } \\
\text { Probabilities } \\
\end{array}$ & $\begin{array}{c}\text { Last-Month } \\
\text { Dummy Model }\end{array}$ & $\begin{array}{c}\text { Last Month } \\
\text { Data }\end{array}$ & $\begin{array}{c}\text { Constant } \\
\text { Misreporting } \\
\text { Probabilities } \\
\end{array}$ & $\begin{array}{c}\text { Variable } \\
\text { Misreporting } \\
\text { Probabilities } \\
\end{array}$ & $\begin{array}{c}\text { Last-Month } \\
\text { Dummy Model }\end{array}$ & $\begin{array}{c}\text { Last Month } \\
\text { Data }\end{array}$ \\
\hline \multicolumn{9}{|l|}{ Changes with respect to: } \\
\hline $\begin{array}{r}\text { Age } \\
(\text { age }=35)-(\text { age }=25)\end{array}$ & $\begin{array}{l}7.471^{* *} \\
(1.069)\end{array}$ & $\begin{array}{l}7.475^{* *} \\
(1.098)\end{array}$ & $\begin{array}{l}6.253^{* *} \\
(0.875)\end{array}$ & $\begin{array}{l}3.619 * * \\
(0.902)\end{array}$ & $\begin{array}{l}5.095^{* *} \\
(0.996)\end{array}$ & $\begin{array}{l}5.099 * * \\
(1.012)\end{array}$ & $\begin{array}{l}4.328^{* *} \\
(0.892)\end{array}$ & $\begin{array}{l}3.455^{* *} \\
(1.005)\end{array}$ \\
\hline $\begin{array}{r}12 \text { years of schooling } \\
(\mathrm{s}=12)-(\mathrm{s}<12)\end{array}$ & $\begin{array}{c}-5.293^{* *} \\
(1.051)\end{array}$ & $\begin{array}{c}-5.295^{* *} \\
(1.126)\end{array}$ & $\begin{array}{c}-6.398 * * \\
(0.977)\end{array}$ & $\begin{array}{c}-6.999 * * \\
(0.992)\end{array}$ & $\begin{array}{l}7.013^{* *} \\
(1.142)\end{array}$ & $\begin{array}{l}7.013^{* *} \\
(1.111)\end{array}$ & $\begin{array}{c}8.813^{* *} \\
(1.026)\end{array}$ & $\begin{array}{c}8.822 * * \\
(1.106)\end{array}$ \\
\hline $\begin{array}{r}\text { Race } \\
\text { (Black - White) }\end{array}$ & $\begin{array}{l}2.524^{*} \\
(1.299)\end{array}$ & $\begin{array}{l}2.584 * * \\
(1.268)\end{array}$ & $\begin{array}{c}1.802 \\
(1.206)\end{array}$ & $\begin{array}{c}1.791 \\
(1.299)\end{array}$ & $\begin{array}{l}-1.074 \\
(1.182)\end{array}$ & $\begin{array}{l}-1.036 \\
(1.218)\end{array}$ & $\begin{array}{c}-4.938^{* *} \\
(1.117)\end{array}$ & $\begin{array}{c}-4.991^{* *} \\
(1.142)\end{array}$ \\
\hline $\begin{array}{r}\text { Race } \\
\text { (Hispanic - White) }\end{array}$ & $\begin{array}{l}2.708^{*} \\
(1.408)\end{array}$ & $\begin{array}{l}2.759^{*} \\
(1.449)\end{array}$ & $\begin{array}{l}2.139 * \\
(1.292)\end{array}$ & $\begin{array}{c}1.402 \\
(1.357)\end{array}$ & $\begin{array}{l}-2.616^{*} \\
(1.534)\end{array}$ & $\begin{array}{l}-2.583^{*} \\
(1.479)\end{array}$ & $\begin{array}{c}-2.773 * * \\
(1.281)\end{array}$ & $\begin{array}{l}-1.630 \\
(1.528)\end{array}$ \\
\hline \multirow[t]{2}{*}{$\begin{array}{r}\text { Number of children less } \\
\text { than } 6 \text { years old } \\
\text { (one - zero) }\end{array}$} & $\begin{array}{l}4.225^{* *} \\
(0.906)\end{array}$ & $\begin{array}{l}4.225^{* *} \\
(0.929)\end{array}$ & $\begin{array}{l}4.512 * * \\
(0.895)\end{array}$ & $\begin{array}{l}5.120 * * \\
(0.954)\end{array}$ & $\begin{array}{l}-1.965^{*} \\
(1.029)\end{array}$ & $\begin{array}{c}-1.967 * * \\
(0.953)\end{array}$ & $\begin{array}{c}-1.940 * * \\
(0.919)\end{array}$ & $\begin{array}{l}-1.299 \\
(0.967)\end{array}$ \\
\hline & $\begin{array}{c}\text { Constant } \\
\text { Misreporting } \\
\text { Probabilities } \\
\end{array}$ & $\begin{array}{c}\text { Variable } \\
\text { Misreporting } \\
\text { Probabilities } \\
\end{array}$ & $\begin{array}{c}\text { Last-Month } \\
\text { Dummy Model }\end{array}$ & $\begin{array}{c}\text { Last Month } \\
\text { Data } \\
\end{array}$ & $\begin{array}{c}\text { Constant } \\
\text { Misreporting } \\
\text { Probabilities } \\
\end{array}$ & $\begin{array}{c}\text { Variable } \\
\text { Misreporting } \\
\text { Probabilities } \\
\end{array}$ & $\begin{array}{c}\text { Last-Month } \\
\text { Dummy Model }\end{array}$ & $\begin{array}{c}\text { Last Month } \\
\text { Data }\end{array}$ \\
\hline $\begin{array}{r}\text { Age } \\
(\text { age }=35)-(\text { age }=25)\end{array}$ & $\begin{array}{l}-0.070 \\
(0.532)\end{array}$ & $\begin{array}{l}-0.077 \\
(0.514)\end{array}$ & $\begin{array}{l}-0.220 \\
(0.847)\end{array}$ & $\begin{array}{c}0.106 \\
(1.261)\end{array}$ & $\begin{array}{l}1.027 * * \\
(0.430)\end{array}$ & $\begin{array}{l}1.029 * * \\
(0.420)\end{array}$ & $\begin{array}{l}5.479 * * \\
(1.052)\end{array}$ & $\begin{array}{l}5.195 * * \\
(1.439)\end{array}$ \\
\hline $\begin{array}{r}12 \text { years of schooling } \\
(\mathrm{s}=12)-(\mathrm{s}<12)\end{array}$ & $\begin{array}{c}-1.940 * * \\
(0.595)\end{array}$ & $\begin{array}{c}-1.940 * * \\
(0.593)\end{array}$ & $\begin{array}{c}-3.057^{* *} \\
(0.961)\end{array}$ & $\begin{array}{l}-3.861^{* *} \\
(1.497)\end{array}$ & $\begin{array}{l}2.970 * * \\
(0.504)\end{array}$ & $\begin{array}{l}2.969 * * \\
(0.503)\end{array}$ & $\begin{array}{l}5.984^{* *} \\
(1.196)\end{array}$ & $\begin{array}{c}4.737 * * \\
(1.671)\end{array}$ \\
\hline $\begin{array}{r}\text { Race } \\
\text { (Black - White) }\end{array}$ & $\begin{array}{l}1.842^{* *} \\
(0.718)\end{array}$ & $\begin{array}{l}1.808 * * \\
(0.730)\end{array}$ & $\begin{array}{l}4.581 * * \\
(1.252)\end{array}$ & $\begin{array}{c}1.214 \\
(1.769)\end{array}$ & $\begin{array}{l}-0.440 \\
(0.590)\end{array}$ & $\begin{array}{l}-0.438 \\
(0.591)\end{array}$ & $\begin{array}{l}-1.079 \\
(1.381)\end{array}$ & $\begin{array}{c}-3.199 * * \\
(1.787)\end{array}$ \\
\hline $\begin{array}{r}\text { Race } \\
\text { (Hispanic - White) }\end{array}$ & $\begin{array}{c}0.435 \\
(0.771)\end{array}$ & $\begin{array}{c}0.407 \\
(0.773)\end{array}$ & $\begin{array}{l}-0.291 \\
(1.224)\end{array}$ & $\begin{array}{l}-2.521 \\
(1.904)\end{array}$ & $\begin{array}{c}0.090 \\
(0.725)\end{array}$ & $\begin{array}{c}0.086 \\
(0.708)\end{array}$ & $\begin{array}{c}1.027 \\
(1.670)\end{array}$ & $\begin{array}{c}1.175 \\
(2.116)\end{array}$ \\
\hline $\begin{array}{r}\text { Number of children less } \\
\text { than } 6 \text { years old } \\
\text { (one - zero) }\end{array}$ & $\begin{array}{l}1.151^{* *} \\
(0.581)\end{array}$ & $\begin{array}{l}1.155^{* *} \\
(0.575)\end{array}$ & $\begin{array}{c}2.096 * * \\
(0.963)\end{array}$ & $\begin{array}{c}3.101^{* *} \\
(1.493)\end{array}$ & $\begin{array}{c}0.165 \\
(0.452)\end{array}$ & $\begin{array}{c}0.164 \\
(0.452)\end{array}$ & $\begin{array}{l}-0.043 \\
(1.102)\end{array}$ & $\begin{array}{c}0.763 \\
(1.424)\end{array}$ \\
\hline
\end{tabular}

Note: See notes to Table 3A. 


\section{Table 4. Misreporting Estimates for the Models Where a Fraction of the Population Never Misreports}

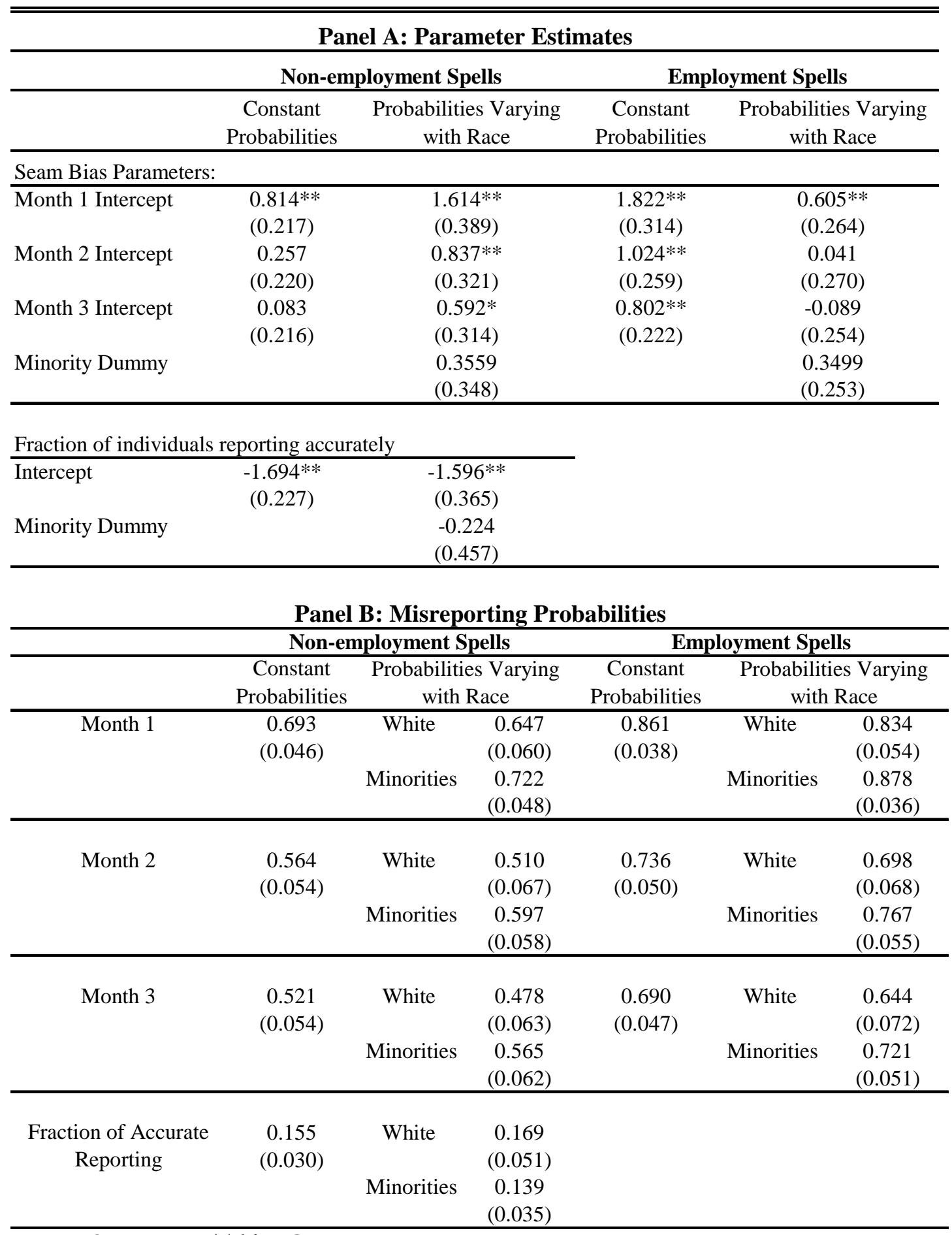

Notes: See notes to Table 2C. 
Table 5. Effect of Changing Policy and Macro Variables on the Fraction of Time Spent in Employment for Different Time Horizons

\begin{tabular}{lccc}
\hline \hline & 3-year Period & 6-year Period & 10-year Period \\
\hline $\begin{array}{l}0.431^{* *} \\
\text { Average Expected Employment }\end{array}$ & $\begin{array}{c}0.439^{* *} \\
(0.009)\end{array}$ & $\begin{array}{c}0.449^{* *} \\
(0.010)\end{array}$ \\
Chaction & & & \\
\hline Maximum welfare benefits & $-0.002^{* *}$ & $-0.003^{* *}$ & $-0.003^{* *}$ \\
increasing by 10\% & $(0.001)$ & $(0.001)$ & $(0.001)$ \\
Carrot waiver & $0.036^{*}$ & $0.039^{*}$ & $0.042^{*}$ \\
(implemented - not implemented) & $(0.020)$ & $(0.022)$ & $(0.023)$ \\
Stick waiver & -0.002 & -0.006 & -0.011 \\
(implemented - not implemented) & $(0.032)$ & $(0.034)$ & $(0.036)$ \\
Minimum wage & 0.002 & 0.002 & 0.003 \\
increasing by 10\% & $(0.010)$ & $(0.011)$ & $(0.011)$ \\
Unemployment rate & & $-0.016^{* *}$ & $-0.018^{* *}$ \\
increasing by 25\% & $(0.005)$ & $(0.005)$ & $(0.005)$ \\
\hline
\end{tabular}

Note: See notes to Table 2A. Standard errors are calculated as described in Section 5.4. 
Figure 1.1

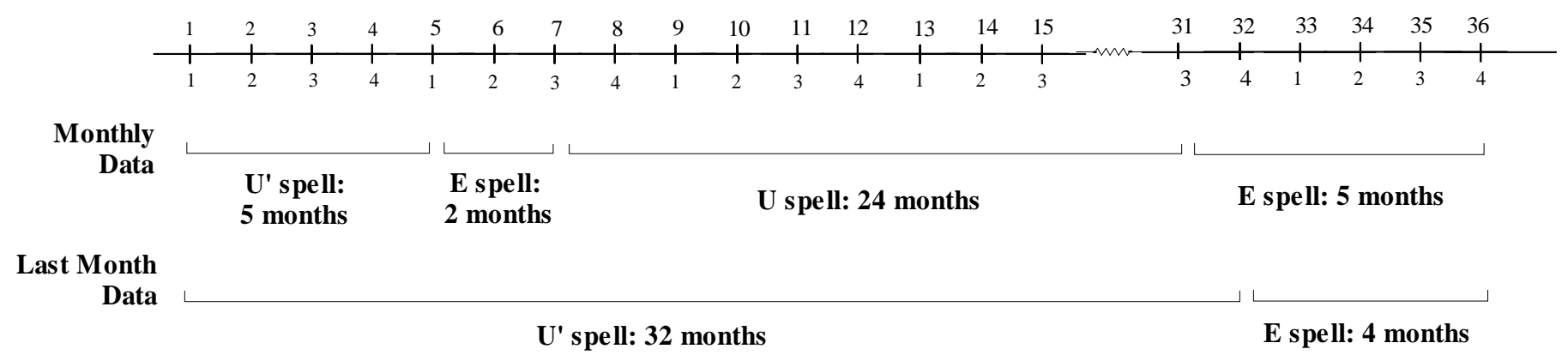

Figure 1.2

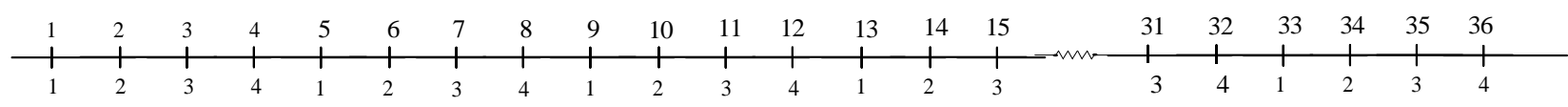

Monthly

$\begin{array}{llll}\text { Data U' spell: } 5 \text { months } & \text { E spell: } 5 \text { months U spell: } 21 \text { months } & \text { E spell: } 5 \text { months }\end{array}$

Last Month
Data $\quad$ U' spell: 8 months $\quad$ E spell: 4 months $\quad$ U spell: 20 months $\quad \downarrow$




\section{Figure 1.3}

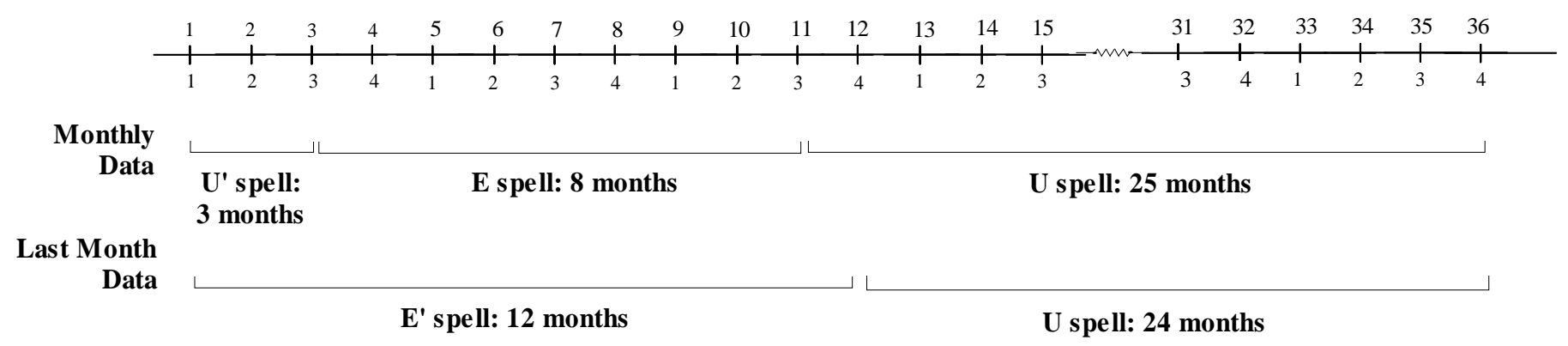

Figure 2

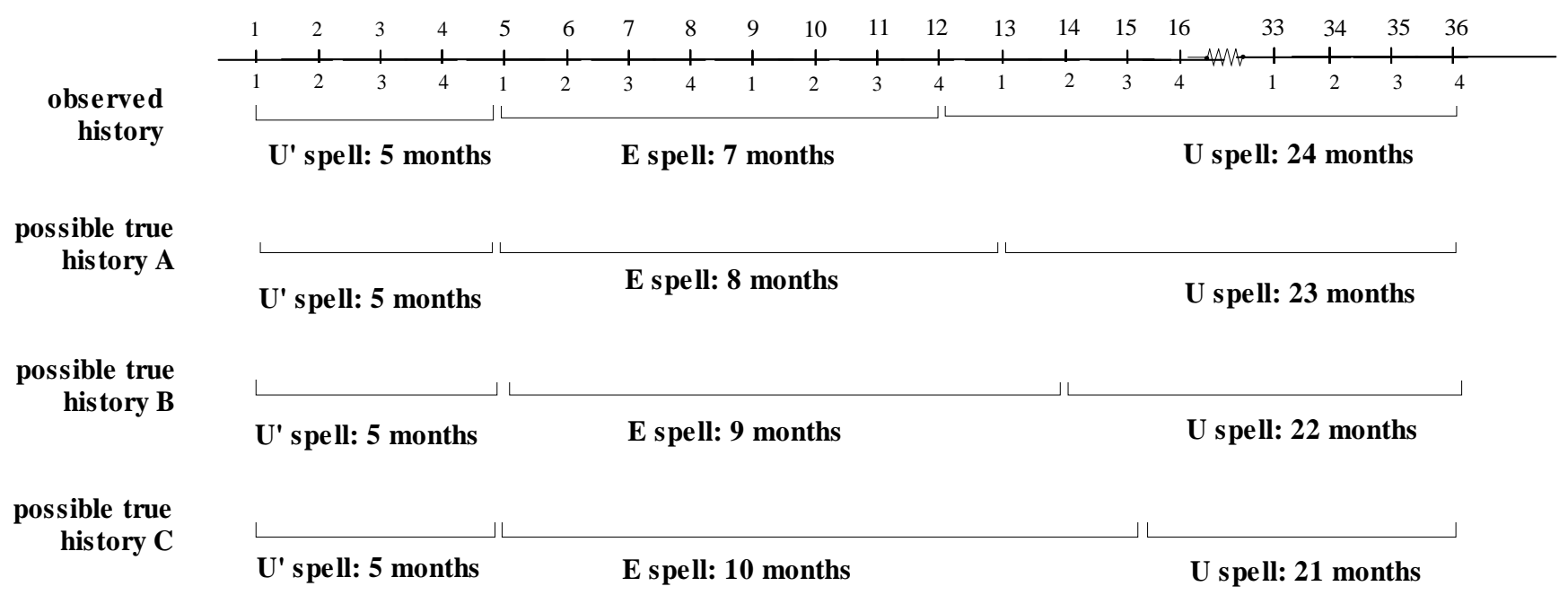




\section{Appendix 1: Identification of Duration Dependence and Seam Bias Parameters in Single Spell Data}

At first glance, it may appear that we have to restrict the form of the duration dependence to identify our model. However, this is not the case, at least for fresh spells. For simplicity we consider a model for employment spells with duration dependence but no explanatory variables and no unobserved heterogeneity. (The argument for non-employment spells is identical.) ${ }^{30}$ One could estimate the parameters of this simplified model using the Analog principle (Manski 1994) by comparing sample moments and their probability limits, which we will refer to as population moments.

Let $m_{j}(k)$ denote the empirical hazard function for spells ending at duration $k$ in reference month $j, j=1,2,3,4$. These are our sample moments; denote their population counterparts by $p_{j}(k)$. To obtain these population moments, first assume that for the population there are $N_{t}$, $N_{t-1}, N_{t-2}$, and $N_{t-3}$ individuals having current durations equal to $t, t-1, t-2$, and $t-3$ in month 4 (over all reference periods). (One may think of $N_{t}, N_{t-1}, N_{t-2}$, and $N_{t-3}$ as being large but finite for now, as they will drop out of the population moments below.)

Regarding the terminology of the duration literature, for $t \geq 4, N_{t}, N_{t-1}, N_{t-2}$, and $N_{t-3}$ represent the total number of individuals at risk at durations $t, t-1, t-2$, and $t-3$ respectively in month 4. As discussed in Section 4.2, we assume that seam bias only occurs when transitions in months 1,2, and 3 of the following reference period are heaped into current month 4 , so $N_{t}, N_{t-1}, N_{t-2}$, and $N_{t-3}$ are not contaminated by seam bias. For month 1 , in large samples the number of individuals who actually enter month 1 at duration $t$ is $N_{t-1} \cdot[1-\lambda(t-1)]$. This is the number of individuals at risk at duration $t$ in month 1, i.e. the difference between the number entering the previous month 4 at duration $t-1$ and the number who leave in the previous month 4 at duration $t-1$. However, note that the number observed to be at risk consists of those actually at risk minus the sum of:

1. The number of individuals who actually left in month 1 at duration $t$ but were observed to exit in the previous month 4 due to seam bias, $N_{t-1} \cdot[1-\lambda(t-1)] \cdot \lambda(t) \cdot \gamma_{1}$;

\footnotetext{
${ }^{30}$ We ignore complications involving identification with explanatory variables since there are many papers on this issue for single spell data with time constant explanatory variables (Elbers and Ridder 1982, Heckman and Singer 1984c). Note further that we have multiple spells for some women to aid in identification (Honore 1993). Identification is also aided in our case by the fact that we have time changing explanatory variables in all types of spells (Eberwein, Ham and LaLonde 1997).
} 
2. The number of individuals who actually left in month 2 at duration $t+1$ but were observed to exit in the previous month 4 due to seam bias $N_{t-1} \cdot[1-\lambda(t-1)] \cdot[1-\lambda(t)] \cdot \lambda(t+1) \cdot \gamma_{2}$; and

3. The number of individuals who actually left in month 3 at duration $t+2$ but were observed to exit in the previous month 4 due to seam bias

$N_{t-1} \cdot[1-\lambda(t-1)] \cdot[1-\lambda(t)] \cdot[1-\lambda(t+1)] \lambda(t+2) \gamma_{3}$.

Of those actually at risk in month 1, in large samples a fraction $\lambda(t)$ actually leave, but only a fraction $\lambda(t) \cdot\left(1-\gamma_{1}\right)$ are observed to have left in month 1 , and the rest $\lambda(t) \cdot \gamma_{1}$ were reported to have left in the previous month 4 due to seam bias. Thus the number observed leaving equals $N_{t-1} \cdot[1-\lambda(t-1)] \cdot \lambda(t) \cdot\left(1-\gamma_{1}\right)$. Given this, we can easily formulate the first population moment condition for the fraction observed to leave in month 1 at duration $t$ (after deleting the common factor $N_{t-1} \cdot[1-\lambda(t-1)]$ from both the numerator and denominator) as

$p_{1}(t)=\frac{\lambda(t) \cdot\left(1-\gamma_{1}\right)}{1-\lambda(t) \cdot \gamma_{1}-[1-\lambda(t)] \cdot \lambda(t+1) \gamma_{2}-[1-\lambda(t)] \cdot[1-\lambda(t+1)] \lambda(t+2) \gamma_{3}}$.

For month 2, the expected number of individuals who actually enter month 2 at duration $t$ is $N_{t-2} \cdot[1-\lambda(t-2)][1-\lambda(t-1)]$. Due to seam bias, the number observed to be at risk in month 2 consists of those actually at risk minus the sum of

1. those who actually left in month 2 at duration $t$ but were observed to exit in the previous month $4, N_{t-2} \cdot[1-\lambda(t-2)][1-\lambda(t-1)] \cdot \lambda(t) \cdot \gamma_{2}$ and

2. those who actually left in month 3 at duration $t+1$ but were observed to exit in the previous month $4, N_{t-2} \cdot[1-\lambda(t-2)][1-\lambda(t-1)] \cdot[1-\lambda(t)] \lambda(t+1) \cdot \gamma_{3}$.

Because of seam bias, the number observed to leave at duration $t$ equals $N_{t-2} \cdot[1-\lambda(t-2)][1-\lambda(t-1)] \cdot \lambda(t) \cdot\left[1-\gamma_{2}\right]$. Thus our second population moment (after deleting the common factor $N_{t-2} \cdot[1-\lambda(t-2)][1-\lambda(t-1)]$ from both the numerator and denominator) is

$p_{2}(t)=\frac{\lambda(t) \cdot\left[1-\gamma_{2}\right]}{1-\lambda(t) \cdot \gamma_{2}-[1-\lambda(t)] \lambda(t+1) \cdot \gamma_{3}}$. 
For month 3, the number of individuals who actually entered month 3 at duration $t$ is $N_{t-3} \cdot[1-\lambda(t-3)][1-\lambda(t-2)][1-\lambda(t-1)]$. Due to seam bias, the number observed to be at risk in month 3 consists of those actually at risk minus those who actually left in month 3 at duration $t$ but were observed to exit in the previous month 4 , $N_{t-3} \cdot[1-\lambda(t-3)][1-\lambda(t-2)] \cdot[1-\lambda(t-1)] \lambda(t) \cdot \gamma_{3}$. The number observed leaving equals $N_{t-3} \cdot[1-\lambda(t-3)][1-\lambda(t-2)] \cdot[1-\lambda(t-1)] \lambda(t) \cdot\left[1-\gamma_{3}\right]$. Thus our third population moment (after deleting the common factor $N_{t-3} \cdot[1-\lambda(t-3)][1-\lambda(t-2)] \cdot[1-\lambda(t-1)]$ from both the numerator and denominator) is

$p_{3}(t)=\frac{\lambda(t) \cdot\left[1-\gamma_{3}\right]}{1-\lambda(t) \cdot \gamma_{3}}$

For month 4, under our assumptions the number of individuals who actually (and were observed to) enter month 4 at duration $t$ is $N_{t}$. The number of individuals who actually leave in month 4 at duration $t$ equals $N_{t} \cdot \lambda(t)$. However due to seam bias, we also observe leaving in month 4

1. $N_{t} \cdot[1-\lambda(t)] \cdot \lambda(t+1) \cdot \gamma_{1}$ individuals who actually left in month 1 of the next reference period but reported leaving in month 4 ,

2. $N_{t} \cdot[1-\lambda(t)][1-\lambda(t+1)] \cdot \lambda(t+2) \cdot \gamma_{2}$ individuals who actually left in month 2 of the next reference period but reported leaving in month 4 and

3. $N_{t} \cdot[1-\lambda(t)][1-\lambda(t+1)] \cdot[1-\lambda(t+2)] \cdot \lambda(t+3) \cdot \gamma_{3}$ individuals who actually left in month 3 of the next reference period but reported leaving in month 4 .

The number of individuals observed leaving in month 4 equals the sum of $N_{t} \cdot \lambda(t)$ and the three terms above. Thus after deleting $N_{t}$ from both the numerator and denominator we have

$$
\begin{aligned}
p_{4}(t)= & \lambda(t)+[1-\lambda(t)] \cdot \lambda(t+1) \cdot \gamma_{1}+[1-\lambda(t)][1-\lambda(t+1)] \cdot \lambda(t+2) \cdot \gamma_{2} \\
& +[1-\lambda(t)][1-\lambda(t+1)] \cdot[1-\lambda(t+2)] \cdot \lambda(t+3) \cdot \gamma_{3} .
\end{aligned}
$$

If we equate population and sample moments, we only have four equations in seven unknowns, $\lambda(t), \lambda(t+1), \lambda(t+2), \lambda(t+3), \gamma_{1}, \gamma_{2}$ and $\gamma_{3}$. However, we can have seven equations in seven unknowns by considering, for example, the additional population moments

$$
p_{3}(t+1)=\frac{\lambda(t+1) \cdot\left[1-\gamma_{3}\right]}{1-\lambda(t+1) \cdot \gamma_{3}},
$$




$$
\begin{aligned}
& p_{3}(t+2)=\frac{\lambda(t+2) \cdot\left[1-\gamma_{3}\right]}{1-\lambda(t+2) \cdot \gamma_{3}} \text { and } \\
& p_{3}(t+3)=\frac{\lambda(t+3) \cdot\left[1-\gamma_{3}\right]}{1-\lambda(t+3) \cdot \gamma_{3}}
\end{aligned}
$$

In fact, the model is actually over-identified, since we have many other moment conditions; for example

$$
\begin{aligned}
& p_{1}(t+1)=\frac{\lambda(t+1) \cdot\left(1-\gamma_{1}\right)}{1-\lambda(t+1) \cdot \gamma_{1}-[1-\lambda(t+1)] \cdot \lambda(t+2) \gamma_{2}-[1-\lambda(t+1)] \cdot[1-\lambda(t+2)] \lambda(t+3) \gamma_{3}} \text { and } \\
& p_{2}(t+1)=\frac{\lambda(t+1) \cdot\left[1-\gamma_{2}\right]}{1-\lambda(t+1) \cdot \gamma_{2}-[1-\lambda(t+1)] \lambda(t+2) \cdot \gamma_{3}},
\end{aligned}
$$

and we now have nine equations in seven unknowns. ${ }^{31}$ Since we can add many more moments without introducing new parameters, the model is significantly over-identified. Of course when the number of equations is greater than or equal to the number of unknowns, this is a necessary, but not sufficient, condition for identification. To pursue this issue further, for the exactly identified models we used several reasonable sets of values for the empirical moments and let Maple solve for the parameters. For each set of empirical moments, we found only one set of real solutions for the parameters when we restricted them to the unit interval.

However, without any auxiliary information, the parameters for the left-censored spells are not identified. Since we measure the duration of these spells from the start of the sample, we will only observe a spell of length $1,5,9,13 \ldots$ ending in month 1 of the reference period, a spell of length $2,6,10,14 \ldots$ ending in month 2 , a spell of length $3,7,11,15 \ldots$ ending in month 3 , or a spell of length $4,8,12,16 \ldots$ ending in month 4 . Adding a superscript $l c$ to denote left-censored spells, for $t \geq 4$ the available population moment conditions are as follows. For $t=5,9,13, \ldots$ we have

$$
p_{1}^{l c}(t)=\frac{\lambda^{l c}(t) \cdot\left(1-\gamma_{1}^{l c}\right)}{1-\lambda^{l c}(t) \cdot \gamma_{1}^{l c}-\left[1-\lambda^{l c}(t)\right] \cdot \lambda^{l c}(t+1) \gamma_{2}^{l c}-\left[1-\lambda^{l c}(t)\right] \cdot\left[1-\lambda^{l c}(t+1)\right] \lambda^{l c}(t+2) \gamma_{3}^{l c}} .
$$

For $t=6,10,14, \ldots$ we have

$$
p_{2}^{\mathrm{lc}}(t)=\frac{\lambda^{l c}(t) \cdot\left[1-\gamma_{2}^{l c}\right]}{1-\lambda^{l c}(t) \cdot \gamma_{2}^{l c}-\left[1-\lambda^{l c}(t)\right] \lambda^{l c}(t+1) \cdot \gamma_{3}^{l c}} .
$$

For $t=7,11,15, \ldots$ we have

\footnotetext{
${ }^{31}$ Here we are abstracting from an endpoint issue. In the last month of the sample, which will be month 4 , we would not expect any misreported transitions, since there are no future spells to misreport from. Thus we assume no misreporting in the last month of the sample, and this will aid in identification.
} 


$$
p_{3}^{l c}(t)=\frac{\lambda^{l c}(t) \cdot\left[1-\gamma_{3}^{l c}\right]}{1-\lambda^{l c}(t) \cdot \gamma_{3}^{l c}}
$$

For $t=8,12,16$ we have

$$
\begin{gathered}
p_{4}^{l c}(t)=\lambda^{l c}(t)+\left[1-\lambda^{l c}(t)\right] \cdot \lambda^{l c}(t+1) \cdot \gamma_{1}^{l c}+\left[1-\lambda^{l c}(t)\right]\left[1-\lambda^{l c}(t+1)\right] \cdot \lambda^{l c}(t+2) \cdot \gamma_{2}^{l c} \\
+\left[1-\lambda^{l c}(t)\right]\left[1-\lambda^{l c}(t+1)\right] \cdot\left[1-\lambda^{l c}(t+2)\right] \cdot \lambda^{l c}(t+3) \cdot \gamma_{3}^{l c} .
\end{gathered}
$$

For $t=4,5,6,7$ we only have four equations in seven unknowns. Unfortunately, if we add four more population conditions for $t=8,9,10,11$, we also will add four more unknowns $\lambda^{l c}(8), \lambda^{l c}(9), \lambda^{l c}(10), \lambda^{l c}(11)$. Thus we now have 8 moments for 11 unknowns and the identification problem remains. However, if we take the estimated seam bias parameters from the fresh employment spells and plug them into the left-censored employment spells, i.e. $\gamma_{k}=\gamma_{k}^{l c}$, for $k=1,2,3$, the number of equations equals the number of unknowns, and the model becomes exactly identified. We thus impose this constraint and an analogous constraint for non-employment spells. Note that this identification problem would disappear if we had information on (and used) the actual start date of the left-censored spells. 
Table A1. Transitions of Employment Spells Ending in Month 4 As a Fraction of All Transitions for Imputed and Non-imputed Data

\begin{tabular}{|c|c|c|c|c|c|c|c|c|}
\hline \multirow[b]{3}{*}{ Year } & \multicolumn{4}{|c|}{ Non-imputed } & \multicolumn{4}{|c|}{ Imputed } \\
\hline & \multicolumn{2}{|c|}{ INTVW=1: self interview } & \multicolumn{2}{|c|}{ INTVW=2: proxy interview } & \multicolumn{2}{|c|}{ INTVW=3: refusal } & \multicolumn{2}{|c|}{ INTVW=4: left the sample } \\
\hline & Percentage & Sample Size & Percentage & Sample Size & Percentage & Sample Size & Percentage & Sample Size \\
\hline 1986 & $48 \%$ & 2481 & $50 \%$ & 1123 & $84 \%$ & 111 & $70 \%$ & 83 \\
\hline 1987 & $54 \%$ & 308 & $51 \%$ & 1105 & $77 \%$ & 174 & $86 \%$ & 95 \\
\hline 1988 & $40 \%$ & 2519 & $49 \%$ & 1030 & $78 \%$ & 105 & $77 \%$ & 97 \\
\hline 1990 & $49 \%$ & 4629 & $55 \%$ & 2166 & $85 \%$ & 331 & $83 \%$ & 332 \\
\hline 1991 & $48 \%$ & 2663 & $52 \%$ & 1301 & $87 \%$ & 151 & $72 \%$ & 120 \\
\hline 1992 & $48 \%$ & 4177 & $53 \%$ & 2271 & $88 \%$ & 346 & $76 \%$ & 238 \\
\hline \multirow[t]{2}{*}{1993} & $50 \%$ & 3837 & $56 \%$ & 1960 & $83 \%$ & 326 & $77 \%$ & 268 \\
\hline & \multicolumn{4}{|c|}{ Mean of Non-imputed } & \multicolumn{4}{|c|}{ Mean of Imputed } \\
\hline
\end{tabular}

